TIMOTHY KAM

KIRDAN LEES

PHILIP LIU

\title{
Uncovering the Hit List for Small Inflation Targeters: A Bayesian Structural Analysis
}

\begin{abstract}
We estimate underlying structural macroeconomic policy objectives of three of the earliest explicit inflation targeters within the context of a small open economy dynamic stochastic general equilibrium model. We assume central banks set policy optimally, such that we can reverse engineer policy objectives from observed time series data. Joint tests of the posterior distributions of these policy preference parameters suggest that the central banks are very similar in their overall objective. None of the central banks show a concern for stabilizing the real exchange rate. All three central banks share a concern for minimizing the volatility in the change in the nominal interest rate. We also show that the resulting optimal policy rule responds to exchange rate movements, even in the case where the central banks do not explicitly care about exchange rate stabilization. This result is also corroborated by results from an alternative simple-rule characterization and estimation of central bank behavior. These last two findings point to the pitfalls of making inferences, from the level of ad hoc simple rules, about what central banks may care about.
\end{abstract}

JEL codes: C51, E52, F41

Keywords: small open economies, optimal policy, structural Bayesian time series.

The authors thank the editor, Masao Ogaki, and an anonymous referee for their comments that have helped improve the paper. Timothy Kam thanks the Reserve Bank of New Zealand for its hospitality while part of the paper was written there, and acknowledges the support of the ANU Faculty of Economics and Commerce FIGS. The authors acknowledge the support of the ANU Supercomputer Facility in making their Linux cluster available. We thank Heather Anderson, Thomas Lubik, Troy Matheson, Warwick McKibbin, Kristoffer Nimark, Adrian Pagan, Simon Potter, Bruce Preston, Farshid Vahid, and seminar participants at WMD2006, ESAM06, the ANU School of Economics, UWA, and the RBA for their input and suggestions. The views expressed in this paper are those of the authors and do not necessarily reflect those of the Reserve Bank of New Zealand.

Тімотну Кам is from the School of Economics \& C.A.M.A., Arndt Building 25a, The Australian National University, ACT 0200, Australia (E-mail: timothy.kam@anu.edu.au). KIRDAN LeEs is at the Economics Department, Reserve Bank of New Zealand, 2 The Terrace, Wellington, 6011, New Zealand \& C.A.M.A. (E-mail: kirdan.lees@rbnz.govt.nz).PHILIP Liv is from C.A.M.A., The Australian National University, ACT 0200,Australia (E-mail: philip.liu@ anu.edu.au).

Received September 5, 2007; and accepted in revised form October 30, 2008.

Journal of Money, Credit and Banking, Vol. 41, No. 4 (June 2009)

(C) 2009 The Ohio State University 
IN THE RECENTLY POPULAR CLASS of dynamic stochastic general equilibrium (DSGE) models, private economic agents such as consumers and firms are often modeled as optimizing decision makers. However, central bank behavior is typically described by a reduced-form monetary policy rule rather than a set of deeper monetary policy objectives often institutionally defined. Empirical estimates obtained from reduced-form monetary policy rules are functions of both the underlying structure of the economy and policy objectives. Characterizing policy from the level of policy objectives allows one to distinguish changes in the policy rule that result from changes to structural parameters in the economy, from, changes in policy objectives.

Modeling the deeper central bank objectives enables us to empirically infer the importance a central bank places on particular institutionally defined monetary policy objectives such as inflation stabilization and output stabilization. In this paper, we apply this simple idea to a new empirical problem for small open economies. We treat the central bank as an optimizing agent, thus placing the central bank on the same footing as the other optimizing agents in the model economy. We identify the macroeconomic objectives of three of the earliest explicit small-open-economy inflation targeters-Australia, Canada, and New Zealand, over the period 1990Q12005Q3. We estimate the same DSGE model for each country and reverse engineer stabilization objectives that are conditioned on the structure of each economy.

Contributions. A considerable number of studies utilize loss function parameters for optimal monetary policy experiments (e.g., Rudebusch and Svensson 1999, Levin and Williams 2003, Del Negro and Schorfheide 2005). However, Dennis (2006) argues that typical loss function parameterizations may be inconsistent with the data. In particular, these yield aggressive policy rules that are inconsistent with the observed interest-rate-smoothing behavior documented in the literature (see Lowe and Ellis 1997).

This paper contributes to this debate by explicitly identifying the loss function parameters for three microfounded small open economies conditioned on historical data. In particular, we ask the questions of (i) whether our sample central banks explicitly care about stabilizing the real exchange rate and (ii) whether their policy preferences are similar overall. In doing so, our approach yields a slightly deeper insight into institutionally defined policy preferences. This is in contrast to empirical analyses (e.g., Lubik and Schorfheide 2007) that inquire into the behavioral responses of central banks. We also provide the link between our empirical analysis of uncovering what central bank preferences are and the resulting implication for policy behavior. We argue and show that it is straightforward to derive the mapping from preferences to equilibrium behavior (i.e., reduced-form policy rules) for the central banks, but the converse is not the case, if we begin the analysis from an ad hoc behavioral rule.

The results from our analysis will help inform monetary policy experiments seeking optimal policy rules for open economy inflation targeters. Estimates of macroeconomic policy objectives can potentially enhance both the transparency and accountability of the practical implementation of monetary policy. Most inflation-targeting 
central banks describe themselves as "flexible" in their approach to inflation targeting, implying central banks objectives embody factors beyond simply inflation. However, while central banks are often explicit about the macroeconomic variables they are concerned with, the trade-offs across these macroeconomic objectives are never elucidated. We believe transparency is enhanced by providing explicit statements of how alternative stabilization objectives are weighted (see Svensson 2005) and our analysis provides such statements.

Finally, historical estimates of stabilization objectives (conditioned on an explicit structural and microfounded model) provide a framework for central bank boards or government agencies tasked with assessing central bank performance. For example, clause 4(b) of New Zealand's 2002 Policy Targets Agreement (PTA), the agreement between the Governor of the Reserve Bank of New Zealand and the Minster of Finance, states: "In pursuing its price stability objective, the Bank shall seek to avoid unnecessary instability in output, interest rates and the exchange rate." Simply observing the unconditional volatilities of the goal variables in the PTA cannot provide an examination of monetary policy, since these volatilities are also affected by nonpolicy structural features of the economy.

Another contribution from our exercise is to provide alternative full-information Bayesian estimates on a popular class of open economy New Keynesian model parameters under the assumption of optimal monetary policy. Our Bayesian posterior estimates may be used for comparison with existing estimation strategies that condition on simple policy rules, or simply for users who wish to calibrate their models for policy simulations.

Main findings. We find that none of the central banks show a concern for stabilizing the real exchange rate. However, all three central banks share a concern for minimizing the volatility in the change in the nominal interest rate. According to our analysis, the Reserve Bank of Australia (RBA) places the most weight on minimizing the deviation of output from trend. In contrast to existing applications of Bayesian econometrics to the evaluation of DSGE models, we also compare the posterior distributions of the central banks' preference parameters. Tests of the posterior distributions of these policy preference parameters suggest that the central banks have very similar preferences.

We also show that the resulting optimal policy rule still responds to exchange rate movements, even in the case where the central banks do not explicitly care about exchange rate stabilization. We also estimate a class of simple rules, as in Lubik and Schorfheide (2007), as an alternative representative of central bank behavior, and this exercise also corroborates the exchange rate response result in the optimal policy. The former optimal rules may be comparable to the simple rules estimates. The latter, as we show, may be misleading when used in empirical exercises to infer what central banks really care about.

Related literature. Several authors report empirical estimates of the objectives of the U.S. Federal Reserve system. Salemi (1995) provides the earliest estimates based on a vector autoregressive (VAR) model. In contrast to the mandate of the Federal Reserve, 
Favero and Rovelli (2003), Castelnuovo and Surico (2004), and Dennis (2006) find either small or insignificant weights on output stabilization over the Volcker-Greenspan period. In addition, Ozlale (2005) and Dennis find a significant weight on interest rate smoothing in the context of aggregate empirical models without explicit optimizing firms and households. Furthermore Cecchetti, McConnell, and Perez-Quiros (2001) present cross-country estimates from a nonstructural model that has little dynamic structure. Nimark (2006) provides estimates of macroeconomic objectives for both the RBA and the Federal Reserve that suggest the RBA puts more weight on output stabilization and interest smoothing than the U.S. Federal Reserve. However, Nimark's paper uses a closed economy model that is silent on any preference for mitigating exchange rate volatility. Given Australia's degree of openness and the focus of this paper, an open economy model appears necessary to approximate the constraint the RBA faces in implementing monetary policy.

In contrast to Nimark (2006), we estimate central bank preferences for Australia, Canada, and New Zealand within an open economy DSGE model. Furthermore, the DSGE model provides an incomplete exchange rate pass-through channel in import prices such that deviations from the law of one price (or alternatively real exchange rate deviations) matter for the economies. Such a model provides a rationale for incorporating central bank preferences over exchange rate movements, as indicated in practice by New Zealand's PTA, for example.

Our DSGE model extends Monacelli (2005) by introducing endogenous persistence on both the aggregate demand and supply sides of the model and has similarities with Justiniano and Preston (Forthcoming). This feature is crucial for bringing the model closer to the data, as shown in Fukac and Pagan (Forthcoming). Thus, for example, a simpler purely forward-looking model used in Lubik and Schorfheide (2007) may be misspecified.

We use Bayesian methods to estimate the model and apply an identical prior to each of the countries in our sample. We make inferences regarding central bank preferences using Bayesian posterior distributions on the model parameters. Our Bayesian methodology closely follows related papers in the literature (see, e.g., Smets and Wouters 2003, Rabanal and Rubio-Ramírez 2005). Although we focus on policy objectives, the estimates from our DSGE model should also help inform a growing empirical open economy literature (see, e.g., Justiniano and Preston Forthcoming, Lubik and Schorfheide 2005, 2007).

The paper is organized as follows. Section 1 sets out the model. Section 2 outlines the empirical methodology and describes the data we use. Sections 3 and 4 contain our main results. We make concluding comments in Section 5.

\section{THE MODEL}

\subsection{The Average Household}

The stylized economy is similar to the open economy model in Monacelli (2005) and Justiniano and Preston (Forthcoming). The economy has identical households 
with a total population of measure 1 . We assume the functional form for period utility

$$
U\left(C_{t}, H_{t}, N_{t}\right)=\frac{\left(C_{t}-H_{t}\right)^{1-\sigma}}{1-\sigma}-\frac{N_{t}^{1+\varphi}}{1+\varphi},
$$

where $C_{t}$ is an index of consumption goods, $H_{t}=h C_{t-1}$ is an external habit stock, with $h \in(0,1)$ capturing the degree of habit persistence, and $N_{t}$ is labor hours. Define the prices for each differentiated home and foreign good of type $i \in[0,1]$ and $j \in$ $[0,1]$, respectively, as $P_{H, t}(i)$ and $P_{F, t}(j)$. Let $B_{t}$ be an Arrow security that pays out contingent on the state of the world and $W_{t} N_{t}$ be the total wage income. The stochastic discount factor is $\mathbb{E}_{t} Q_{t, t+1}$ such that it will be inversely related to the gross return on a nominal riskless one-period bond, $\mathbb{E}_{t} Q_{t, t+1}=R_{t}^{-1}$.

The price-taking average household solves a Bellman equation problem

$$
V\left(B_{t}, H_{t}\right)=\max _{C_{t}, N_{t}} U\left(C_{t}, H_{t}, N_{t}\right)+\beta \mathbb{E}_{t}\left\{V\left(B_{t+1}, H_{t+1}\right)\right\} ; \quad \beta \in(0,1)
$$

subject to the sequence of budget constraints

$$
B_{t} \geq \int_{0}^{1} \int_{0}^{1}\left[P_{H, t}(i) C_{H, t}(i)+P_{F, t}(j) C_{F, t}(j)\right] d i d j+\mathbb{E}_{t} Q_{t, t+1} B_{t+1}-W_{t} N_{t}
$$

with $B_{0}$ given.

The consumption index $C_{t}$ is linked to a continuum of domestic, $C_{H, t}(i)$, and foreign goods, $C_{F, t}(j)$, which exist on the interval of $[0,1]$ where

$$
C_{t}=\left[(1-\alpha)^{\frac{1}{\eta}} C_{H, t}^{\frac{\eta-1}{\eta}}+\alpha^{\frac{1}{\eta}} C_{F, t}^{\frac{\eta-1}{\eta}}\right]^{\frac{\eta-1}{\eta}},
$$

and

$$
C_{H, t}=\left[\int_{0}^{1} C_{H, t}(i)^{\frac{\varepsilon-1}{\varepsilon}} d i\right]^{\frac{\varepsilon}{\varepsilon-1}}, \quad C_{F, t}=\left[\int_{0}^{1} C_{F, t}(j)^{\frac{\varepsilon-1}{\varepsilon}} d j\right]^{\frac{\varepsilon}{\varepsilon-1}} .
$$

The elasticity of substitution between home and foreign goods is given by $\eta>0$ and the elasticity of substitution between goods within each goods category (home and foreign) is $\varepsilon>0$. Optimal allocation of the household expenditure across each good type gives rise to the demand functions

$$
C_{H, t}(i)=\left(\frac{P_{H, t}(i)}{P_{H, t}}\right)^{-\varepsilon} C_{H, t}, \quad C_{F, t}(j)=\left(\frac{P_{F, t}(j)}{P_{F, t}}\right)^{-\varepsilon} C_{F, t}
$$

for all $i, j \in[0,1]$, where the aggregate price levels are defined as

$$
P_{H, t}=\left(\int_{0}^{1} P_{H, t}(i)^{1-\varepsilon} d i\right)^{\frac{1}{1-\varepsilon}}, \quad P_{F, t}=\left(\int_{0}^{1} P_{F, t}(j)^{1-\varepsilon} d j\right)^{\frac{1}{1-\varepsilon}},
$$


and optimal consumption demand of home and foreign goods can be derived, respectively, as

$$
C_{H, t}=(1-\alpha)\left(\frac{P_{H, t}}{P_{t}}\right)^{-\eta} C_{t}, \quad C_{F, t}=\alpha\left(\frac{P_{F, t}}{P_{t}}\right)^{-\eta} C_{t} .
$$

Substitution of these demand functions into (4) yields the consumer price index as

$$
P_{t}=\left[(1-\alpha) P_{H, t}^{1-\eta}+\alpha P_{F, t}^{1-\eta}\right]^{\frac{1}{1-\eta}}
$$

The intratemporal condition relating labor supply (the marginal rate of substitution between consumption and leisure) to the real wage (the marginal product of labor) must also be satisfied

$$
\left(C_{t}-H_{t}\right)^{\sigma} N_{t}^{\varphi}=\frac{W_{t}}{P_{t}} .
$$

Finally, intertemporal optimality for the household decision problem must satisfy

$$
\beta\left(\frac{C_{t+1}-H_{t+1}}{C_{t}-H_{t}}\right)^{-\sigma}\left(\frac{P_{t}}{P_{t+1}}\right) \mu_{t}\left(h^{t+1} \mid h^{t}\right)=Q_{t, t+1}
$$

for all dates and state $t \in \mathbb{N}$, and $\mu_{t}\left(h^{t+1} \mid h^{t}\right)$ denotes the probability measure on the continuation history (or state, in the Markovian case), conditional on the realized history. Taking conditional expectations yields the familiar stochastic Euler equation

$$
\beta R_{t} \mathbb{E}_{t}\left\{\left(\frac{C_{t+1}-H_{t+1}}{C_{t}-H_{t}}\right)^{-\sigma}\left(\frac{P_{t}}{P_{t+1}}\right)\right\}=1 .
$$

\subsection{International Risk Sharing and Relative Prices}

The rest of the world, denoted by variables and parameters with an asterisk, solves a similar problem to the small open economy. Specifically, the rest of the world is the limiting case of a closed economy, where $\alpha^{*} \rightarrow 1$. First-order conditions for optimal labor supply and consumption, analogues of (9) and (10), also hold for the rest of the world, also hold. Given identical global preferences and complete international markets, we obtain perfect risk sharing,

$$
\beta\left(\frac{C_{t+1}-H_{t+1}}{C_{t}-H_{t}}\right)^{-\sigma}\left(\frac{P_{t}}{P_{t+1}}\right)=Q_{t, t+1}=\beta\left(\frac{C_{t+1}^{*}-H_{t+1}^{*}}{C_{t}^{*}-H_{t}^{*}}\right)^{-\sigma}\left(\frac{P_{t}^{*}}{P_{t+1}^{*}}\right)\left(\frac{\tilde{e}_{t}}{\tilde{e}_{t+1}}\right)
$$

for all dates and states, and where $\tilde{e}_{t}$ is the nominal exchange rate. We also define conventionally the real exchange rate as 


$$
\mathcal{Q}_{t}=\tilde{e}_{t} P_{t}^{*} / P_{t}
$$

Assuming ex ante identical countries, and no preference shocks to the rest of the world, this implies that

$$
C_{t}-h C_{t-1}=\vartheta^{*}\left(C_{t}^{*}-h C_{t-1}^{*}\right) \mathcal{Q}_{t}^{\frac{1}{\sigma}},
$$

where $\vartheta^{*}=1$ imposes ex ante symmetry of countries and zero net foreign asset holdings.

Let $c_{t}:=\ln \left(C_{t} / C_{s s}\right), y_{t}^{*}:=\ln \left(Y_{t}^{*} / Y_{s \mathrm{~s}}^{*}\right)=\ln \left(C_{t}^{*} / C_{s \mathrm{~s}}^{*}\right)$, and $q_{t}:=\ln \left(\mathcal{Q}_{t} / \mathcal{Q}_{t}^{*}\right)$, denote the percentage deviation of home consumption, foreign output, and real exchange rate from their respective steady states, where $X_{s s}$ is the deterministic steady state value of a variable $X_{t}$. Then, a log-linear approximation of (13) is

$$
c_{t}-h c_{t-1}=y_{t}^{*}-h y_{t-1}^{*}+\frac{1-h}{\sigma} q_{t} .
$$

Complete markets thus imply that global consumption will be perfectly correlated in the absence of deviations in the real exchange rate.

From (11) we can also derive the no-arbitrage condition for exchange rates, or the uncovered interest parity condition

$$
R_{t}-R_{t}^{*} \frac{\tilde{e}_{t}}{\tilde{e}_{t+1}}=0,
$$

which must hold for all states and dates in a globally complete markets setting. A log-linear approximation of this, and taking expectations with respect to the time $t$ sigma algebra, yields the familiar nominal interest parity condition

$$
\mathbb{E}_{t} e_{t+1}-e_{t}=r_{t}-r_{t}^{*},
$$

where $e_{t}:=\ln \left(\tilde{e}_{t} / e_{s s}\right)$, and the domestic and foreign rates of return are $r_{t}=R_{t}-1$ and $r_{t}^{*}=R_{t}^{*}-1$, respectively.

We can define the terms of trade as the ratio of the foreign goods price index to the home goods price index. In log-linear terms this is

$$
s_{t}=p_{F, t}-p_{H, t} .
$$

\subsection{Production and Optimal Pricing}

There exist continua of monopolistically competitive domestic producers $i \in[0$, 1] that produce differentiated goods and import retailers $j \in[0,1]$ that add markups to goods imported at world prices. We employ similar pricing assumptions as in Justiniano and Preston (Forthcoming) and Smets and Wouters (2003). In particular, the conventional Calvo-style optimal pricing models and partial inflation indexation for nonoptimizing price setters. This allows inflation to be partly a jump variable and also partially backward looking. 
Domestic goods firms. Domestic goods firms operate a linear production technology, $Y_{H, t}(i)=\epsilon_{a, t} N_{t}(i)$ where $\epsilon_{a, t}$ is an exogenous domestic technology shock. Domestic firms face an independent signal that allows them to set prices optimally each period with probability $1-\theta_{H}$. In each period $t$, the remaining fraction $\theta_{H} \in(0,1)$ of firms partially index their price to take into account of aggregate domestic inflation according to the simple rule

$$
P_{H, t}(i)=P_{H, t-1}(i)\left(\frac{P_{H, t-1}}{P_{H, t-2}}\right)^{\delta_{H}},
$$

where $\delta_{H} \in[0,1]$ measures the degree of inflation indexation. Since all firms either receive the same signal to reset prices or do not receive any signal, they will choose the same pricing strategies. Given Calvo price setting, it is straightforward to define the dynamics of the aggregate price level of the domestic goods. In particular, define the evolution of the aggregate home goods price index as

$$
P_{H, t}=\left\{\left(1-\theta_{H}\right)\left(P_{H, t}^{n e w}\right)^{1-\varepsilon}+\theta_{H}\left[P_{H, t-1}\left(\frac{P_{H, t-1}}{P_{H, t-2}}\right)^{\delta_{H}}\right]^{1-\varepsilon}\right\}^{\frac{1}{1-\varepsilon}} .
$$

Consider a candidate firm $i$ that had set its price optimally in time $t$ as $P_{H, t}(i)$. Suppose at some time $t+s, s \geq 0$, the price $P_{H, t}(i)$ still prevails. Then the firm will have to face the demand for its product given by the demand constraint

$$
Y_{H, t+s}(i)=\left[\frac{P_{H, t}(i)}{P_{H, t+s}}\left(\frac{P_{H, t+s-1}}{P_{H, t-1}}\right)^{\delta_{H}}\right]^{-\varepsilon}\left(C_{H, t+s}+C_{H, t+s}^{*}\right) .
$$

Note that market demand at time $t+s$ will take into account the inflation indexation between $t$ and $t+s$.

Firms that set optimal prices do so to maximize their present value of the stochastic stream of profits. A candidate firm $i$ solves

$$
\begin{aligned}
& \max _{P_{H, t}(i)} \mathbb{E}_{t} \sum_{s=0}^{\infty} Q_{t, t+s} \theta_{H}^{s} Y_{H, t+s}(i) \\
& \quad \times\left[P_{H, t}(i)\left(\frac{P_{H, t+s-1}}{P_{H, t-1}}\right)^{\delta_{H}}-P_{H, t+s} M C_{H, t+s} \exp \left(\epsilon_{H, t+s}\right)\right]
\end{aligned}
$$

subject to (20) for $t, s \in \mathbb{N}$ and the technological constraint given by real marginal cost,

$$
M C_{H, t+s}=\frac{W_{t+s}}{\epsilon_{a, t+s} P_{H, t+s}} .
$$

Note that we also allow for a structural shock to real marginal cost given by $\epsilon_{H, t} \sim$ i.i.d. $\left(0, \sigma_{H}\right)$. This has the interpretation of an independent cost-push shock to domestic goods producers. 
The first-order necessary condition characterizing domestic firms' optimal pricing function in a symmetric equilibrium is

$$
\begin{aligned}
& \mathbb{E}_{t} \sum_{s=0}^{\infty} \theta_{H}^{s} Q_{t, t+s} Y_{H, t+s}(i) \\
& \quad \times\left[\tilde{P}_{H, t}\left(\frac{P_{H, t+s-1}}{P_{H, t-1}}\right)^{\delta_{H}}-\left(\frac{\varepsilon}{\varepsilon-1}\right) P_{H, t+s}(i) M C_{H, t+s} \exp \left(\epsilon_{H, t+s}\right)\right]=0 .
\end{aligned}
$$

Let the home goods inflation rate be $\pi_{H, t}:=\ln \left(P_{H, t} / P_{H, t-1}\right)$ and $y_{t}:=\ln \left(Y_{t} / Y_{s s}\right)$ be the percentage deviation of home output from steady state. Denote the real marginal cost in percentage deviation terms from its deterministic steady-state $m c_{H, s \mathrm{~s}}=[\epsilon /(\epsilon-$ $1)]^{-1}$ as $m c_{H, t}$. In Appendix A, we derive the log-linear approximation of the optimal pricing decision rule, which can easily be expressed as the following Phillips curve for domestic goods inflation:

$$
\pi_{H, t}-\delta_{H} \pi_{H, t-1}=\beta\left(\mathbb{E}_{t} \pi_{H, t+1}-\delta_{H} \pi_{H, t}\right)+\lambda_{H}\left(m c_{H, t}+\epsilon_{H, t}\right),
$$

where $\lambda_{H}=\left(1-\beta \theta_{H}\right)\left(1-\theta_{H}\right) \theta_{H}^{-1}$ and

$$
m c_{H, t}=\varphi y_{t}-(1+\varphi) \epsilon_{a, t}+\alpha s_{t}+\frac{\sigma}{1-h}\left(y_{t}^{*}-h y_{t-1}^{*}\right)+q_{t}+\epsilon_{c, t} .
$$

Import retail firms. Import retailers are assumed to purchase imported goods at competitive world prices. However, these firms act as monopolistically competitively redistributors of these goods. This creates a gap between the price of imported goods in domestic currency terms and the domestic retail price of imported goods. Define this law of one price (LOP) gap in log-linear terms as

$$
\psi_{F, t}=e_{t}+p_{t}^{*}-p_{F, t} .
$$

The pricing behavior for imports retailers is similar to that of domestic goods producers. In short, the evolution of the imports price index is given by

$$
P_{F, t}=\left\{\left(1-\theta_{F}\right)\left(P_{F, t}^{n e w}\right)^{1-\varepsilon}+\theta_{F}\left[P_{F, t-1}\left(\frac{P_{F, t-1}}{P_{F, t-2}}\right)^{\delta_{F}}\right]^{1-\varepsilon}\right\}^{\frac{1}{1-\varepsilon}}
$$

An importing firm $j$ at some time $t+s, s \geq 0$, faces the demand for its product given by the demand constraint

$$
Y_{F, t+s}(j)=\left[\frac{P_{F, t}(j)}{P_{F, t+s}}\left(\frac{P_{F, t+s-1}}{P_{F, t-1}}\right)^{\delta_{F}}\right]^{-\varepsilon} C_{F, t+s} .
$$


Note that market demand at time $t+s$ will take into account the inflation indexation between $t$ and $t+s$. A candidate firm $j$ solves

$$
\begin{aligned}
& \max _{P_{F, t}(j)} \mathbb{E}_{t} \sum_{s=0}^{\infty} Q_{t, t+s} \theta_{F}^{s} Y_{F, t+s}(j) \\
& \quad \times\left[P_{F, t}(j)\left(\frac{P_{F, t+s-1}}{P_{F, t-1}}\right)^{\delta_{F}}-\tilde{e}_{t+s} P_{F, t+s}^{*}(j) \exp \left(\epsilon_{F, t+s}\right)\right]
\end{aligned}
$$

subject to (28) for $t, s=0,1, \ldots$. Here we also allow for a structural shock to marginal cost (world price of good $j$ ) given by $\epsilon_{F, t} \sim$ i.i.d. $\left(0, \sigma_{F}\right)$. This has the interpretation of an independent cost-push shock to imports retailers.

The first order necessary condition characterizing the import retailers' optimal pricing function in the symmetric equilibrium is

$$
\begin{aligned}
& \mathbb{E}_{t} \sum_{s=0}^{\infty} \theta_{F}^{s} Q_{t, t+s} Y_{F, t+s}(j) \\
& \quad \times\left[\tilde{P}_{F, t}\left(\frac{P_{F, t+s-1}}{P_{F, t-1}}\right)^{\delta_{F}}-\left(\frac{\varepsilon}{\varepsilon-1}\right) \tilde{e}_{t+s} P_{F, t+s}(j) \exp \left(\epsilon_{F, t+s}\right)\right]=0 .
\end{aligned}
$$

Let $\pi_{F, t}:=\ln \left(P_{F, t} / P_{F, t-1}\right)$. Log-linearizing this around the nonstochastic steady state yields

$$
\pi_{F, t}=\beta \mathbb{E}_{t}\left(\pi_{F, t+1}-\delta_{F} \pi_{F, t}\right)+\delta_{F} \pi_{F, t-1}+\lambda_{F}\left(\psi_{F, t}+\epsilon_{F, t}\right),
$$

where $\lambda_{F}=\left(1-\beta \theta_{F}\right)\left(1-\theta_{F}\right) \theta_{F}^{-1}$.

\subsection{Terms of Trade, Real Exchange Rate, and Market Clearing}

We can derive a relationship between the terms of trade, the real exchange rate, and the LOP gap. Specifically, log-linearizing the real exchange rate definition (12) around the deterministic steady state we have

$$
q_{t}=e_{t}+p_{t}^{*}-p_{t}
$$

From (26) we can rewrite this as

$$
q_{t}=\psi_{F, t}+p_{F, t}-p_{t} \approx \psi_{F, t}-(1-\alpha)\left(p_{F, t}-p_{H, t}\right)=\psi_{F, t}-(1-\alpha) s_{t},
$$

where the last term is obtained by log-linearizing the CPI definition and then using (17).

The remaining market-clearing condition to consider is in the product markets. In the rest of the world we have the limit of a closed economy so that $y_{t}^{*}=c_{t}^{*}$ for all $t$. In the small open economy, this requires that domestic output equals total domestic 
and foreign demand for home produced goods. In log-linear terms this is

$$
y_{t}=c_{H, t}+c_{H, t}^{*} .
$$

Since the demand for home and foreign consumption goods can be written in log-linear form as $c_{H, t}=(1-\alpha)\left[\alpha \eta s_{t}+c_{t}\right]$ and $c_{H, t}^{*}=\alpha\left[\eta\left(s_{t}+\psi_{F, t}\right)+y_{t}^{*}\right]$, respectively, we can write

$$
y_{t}=(2-\alpha) \alpha \eta s_{t}+(1-\alpha) c_{t}+\alpha \eta \psi_{F, t}+\alpha y_{t}^{*} .
$$

\subsection{Log-Linear Approximation of the Model}

In this section, we summarize the log-linearized equilibrium conditions. The consumption Euler equation is obtained by log-linearizing (10) and taking expectations conditional on the time $t$ sigma algebra

$$
c_{t}-h c_{t-1}=\mathbb{E}_{t}\left(c_{t+1}-h c_{t}\right)-\frac{1-h}{\sigma}\left(r_{t}-\mathbb{E}_{t} \pi_{t+1}\right) .
$$

Domestic goods inflation is given by (24) and substituting out the term $m c_{H, t}$ :

$$
\begin{aligned}
\pi_{H, t}= & \beta \mathbb{E}_{t}\left(\pi_{H, t+1}-\delta_{H} \pi_{H, t}\right)+\delta_{H} \pi_{H, t-1} \\
& +\lambda_{H}\left[\varphi y_{t}-(1+\varphi) \epsilon_{a, t}+\alpha s_{t}+\frac{\sigma}{1-h}\left(c_{t}-h c_{t-1}\right)\right]+\lambda_{H} \epsilon_{H, t} .
\end{aligned}
$$

Imports inflation is given by (31) and substituting out the term $\psi_{F, t}$ with (33)

$$
\pi_{F, t}=\beta \mathbb{E}_{t}\left(\pi_{F, t+1}-\delta_{F} \pi_{F, t}\right)+\delta_{F} \pi_{F, t-1}+\lambda_{F}\left[q_{t}-(1-\alpha) s_{t}\right]+\lambda_{F} \epsilon_{F, t} .
$$

Leading (32) one period, first-differencing, taking the time $t$ conditional expectations operator, and then combining with (16) yields the real interest parity condition,

$$
\mathbb{E}_{t}\left(q_{t+1}-q_{t}\right)=\left(r_{t}-\mathbb{E}_{t} \pi_{t+1}\right)-\left(r_{t}^{*}-\mathbb{E}_{t} \pi_{t+1}^{*}\right)+\epsilon_{q, t} .
$$

First-differencing the terms of trade equation (17) we have

$$
s_{t}-s_{t-1}=\pi_{F, t}-\pi_{H, t}+\epsilon_{s, t} .
$$

Goods market clearing (34) in combination with (26) yields

$$
y_{t}=(1-\alpha) c_{t}+\alpha \eta q_{t}+\alpha \eta s_{t}+\alpha y_{t}^{*} .
$$

First-differencing the CPI definition yields CPI inflation,

$$
\pi_{t}=(1-\alpha) \pi_{H, t}+\alpha \pi_{F, t} .
$$


Exogenous stochastic processes for terms-of-trade, technology, and real-interestparity shocks

$$
\epsilon_{j, t}=\rho_{j} \epsilon_{j, t-1}+v_{j, t} ; \quad \rho_{j} \in(0,1), v_{j} \sim \text { i.i.d. }\left(0, \sigma_{j}^{2}\right)
$$

for $j=s, a, q$. Recall the marginal cost shocks in the home goods and import retailers profit functions are $\epsilon_{H} \sim$ i.i.d. $\left(0, \sigma_{H}\right)$ and $\epsilon_{F} \sim$ i.i.d. $\left(0, \sigma_{F}\right)$, respectively.

Finally, for simplicity we assume that the foreign processes $\left\{\pi^{*}, y^{*}, r^{*}\right\}$ are given by uncorrelated $\mathrm{AR}(1)$ processes $^{1}$

$$
\left(\begin{array}{c}
\pi_{t}^{*} \\
y_{t}^{*} \\
r_{t}^{*}
\end{array}\right)=\left(\begin{array}{ccc}
a_{1} & 0 & 0 \\
0 & b_{2} & 0 \\
0 & 0 & c_{3}
\end{array}\right)\left(\begin{array}{l}
\pi_{t-1}^{*} \\
y_{t-1}^{*} \\
r_{t-1}^{*}
\end{array}\right)+\left(\begin{array}{ccc}
\sigma_{\pi^{*}} & 0 & 0 \\
0 & \sigma_{y^{*}} & 0 \\
0 & 0 & \sigma_{r^{*}}
\end{array}\right)\left(\begin{array}{l}
v_{\pi^{*}, t} \\
v_{y^{*}, t} \\
v_{r^{*}, t}
\end{array}\right),
$$

where $\left(v_{\pi^{*}, t}, v_{y^{*}, t}, v_{r^{*}, t}\right) \sim N\left(0, I_{3}\right)$.

\subsection{Central Bank Preferences}

Since the model possesses incomplete exchange rate pass through in the short run (which gives rise to persistent gaps in the law of one price for imported goods) there is a potential role for the central bank to minimize these gaps. Alternatively, given the terms of trade $s_{t}$ from equation (33), the central bank can target the real exchange rate $q_{t}$ to stabilize these law of one price gaps, $\psi_{F, t}$.

Let $\tilde{\pi}_{t}:=\sum_{i=0}^{3} \pi_{t-i} / 4$ denote the annual inflation rate in the quarterly model. For computational and estimation purposes, we suppose the one-period general loss function for the central bank is quadratic ${ }^{2}$

$$
L\left(\tilde{\pi}_{t}, y_{t}, q_{t}, r_{t}-r_{t-1}\right)=\frac{1}{2}\left[\tilde{\pi}_{t}^{2}+\mu_{y} y_{t}^{2}+\mu_{q} q_{t}^{2}+\mu_{r}\left(r_{t}-r_{t-1}\right)^{2}\right] .
$$

The parameters $\mu_{y}, \mu_{q}, \mu_{r} \in[0,+\infty)$ express the concern with output stabilization, real exchange rate stabilization and targeted interest rate smoothing, respectively. These objectives are expressed relative to a concern for annual inflation, $\tilde{\pi}_{t}$, that is, normalized to one. This specification of macroeconomic objectives encompasses the expressed goals of so-called "flexible" inflation targeting central banks by allowing for positive weights to the arguments other than inflation in the loss function.

In addition to the output argument, our loss function specification includes a weight on the change in the interest rate. Central banks typically change policy in successive

1. Our earlier estimates have also utilized assumptions on $\left\{\pi^{*}, y^{*}, r^{*}\right\}$ as being generated by a VAR(1) process and also a limiting closed economy New Keynesian model under a first best fiscal-monetary policy arrangement. The former is statistically more flexible than our current assumption, and the latter is a stricter theoretical restriction on the data. We found that these assumptions do not matter very much. Thus, a reasonable middle ground for statistical flexibility and parsimony in our model parameterization would be to use our current assumption.

2. Our aim is recover the macroeconomic objectives of open economy central banks. We take no stance on normative design aspects of what these objectives should be. Rather, we simply seek what our three open economy inflation targeters have tried to achieve over the sample period. 
incremental changes in the policy rate in the same direction and many papers included the change in the interest rate in the loss function (see, e.g., Svensson 2000). Empirically the change in the interest rate term matters. Dennis (2006) shows that a high weight should be attached to the change in interest rates to capture the dynamics on interest rates in the U.S. data. Furthermore, we allow for the possibility that our open economy central banks may be concerned with stabilizing the real exchange rate. Obstfeld and Rogoff (1998) suggest there are costs to exchange rate volatility that generates consumption volatility and costly hedging activities on the part of firms, although Bergin, Shin, and Tchakarov (2007) demonstrate that the costs of exchange rate volatility may be small.

From a public finance perspective, such assignments of policy objective functions are clearly ad hoc. For example, the literature following the method of deriving an approximate private-welfare-based loss function in Woodford (2003) would argue that the loss function parameters are not "free" but must be constrained by the preferences of the representative household. However, in defense of our approach we make three arguments.

First, mapping a second-order approximation of the welfare maximizing centralbank loss function from household preferences in closed form (see, e.g., Benigno and Woodford 2008) generally imposes highly nonlinear structural restrictions on the loss function parameters. Since these restrictions on the approximate loss function are likely to be misspecified with respect to, or too demanding on, the empirical data-generating process, we have chosen to treat the loss function parameters as free. Second, from an empirical perspective our loss function captures the goal variables Australia, Canada, and New Zealand have institutionally defined as monetary policy objectives. In the case of New Zealand, there is a legislated set of policy objectives: price stability, output, interest rates, and the exchange rate. Finally, our formulation of objectives is consistent with the monetary policy literature that seeks to evaluate the efficacy of alternative monetary policy rules using quadratic loss functions (see, e.g., Rudebusch and Svensson 1999, Levin and Williams 2003).

Optimal time-consistent monetary policy. To keep the empirical structure arising from optimal policy manageable, we assume that the central bank must implement optimal policy which is time consistent. In particular, we restrict our notion of time consistency to a class of dynamic games characterized by Markov-perfect equilibrium payoffs and strategies. ${ }^{3}$

Define $W\left(\epsilon_{t}, z_{t-1}\right)$ as the value function of the central bank's optimal action at time $t$ given state $z_{t-1}:=\left\{c_{t-1}, y_{t-1}^{*}, \pi_{H, t-1}, \pi_{F, t-1}\right\}$ and $\epsilon_{t}:=\left(\pi_{t}^{*}, y_{t}^{*}, r_{t}^{*}\right.$, $\left.\left\{\epsilon_{j, t}\right\}\right)$, for $j=s, a, H, F, q$. A strategy of the central bank is a sequence of policy functions $\left\{r_{t}\left(\epsilon_{t}, z_{t-1}\right)\right\}_{t=0}^{\infty}$ and the private sector's collective strategy would be the sequence of allocation and pricing functions $\left\{c_{t}, \pi_{H, t}, \pi_{F, t}, q_{t}, s_{t}, y_{t}\right\}_{t=0}^{\infty}$. In principle, we can and we do, characterize our Markov-perfect equilibrium as if it were

3. Our methodology also encodes the option for solving and estimating the model under the assumption that central banks commit to an optimal monetary policy plan. However, this alternative assumption would be beyond the scope of this paper. 
supported by central bank strategies that involve picking a sequence of all pricing and allocation functions, and private sector strategies then would be to pick expectations of such future outcomes under the central bank strategy which are consistent with the equilibrium definition. More precisely, we define an equilibrium under time-consistent optimal monetary policy as follows.

Definition 1 (Linear-quadratic Markov-perfect equilibrium (LQ-MPE)). A LQ-MPE in this economy is a sequence of allocation and pricing functions,

$$
\left\{u_{t}\left(\epsilon_{t}, z_{t-1}\right)\right\}_{t=0}^{\infty}:=\left\{c_{t}, \pi_{H, t}, \pi_{F, t}, q_{t}, r_{t}, s_{t}, y_{t}\right\}_{t=0}^{\infty},
$$

that satisfies:

(i) The central bank's Bellman equation,

$$
W\left(\epsilon_{t}, z_{t-1}\right)=\min _{u_{t}} L\left(\tilde{\pi}_{t}, y_{t}, q_{t}, r_{t}-r_{t-1},\right)+\beta \mathbb{E}_{t} W\left(\epsilon_{t+1}, z_{t}\right)
$$

subject to (35)-(41).

(ii) Private sector competitive equilibrium conditions (35)-(41) with conditional expectations consistent with the solution to the problem (45).

(iii) Given the exogenous stochastic processes (42) and (43).

Notice that the central bank takes private expectations as given when it sequentially optimizes. We compute solutions to the familiar LQ-MPE problem using the algorithm of Dennis (2004). In the existing Bayesian literature on such models, one often estimates a reduced-form Taylor type rule. However, when the central bank optimizes under discretion, it can be shown, as in Dennis, that policy preference parameters and deep parameters place nonlinear constraints on a reduced-form policy feedback rule. To make the model stochastically richer, we will linearly append a noise term to the resulting optimal interest rate rule, $r_{t}\left(\epsilon_{t}, z_{t-1}\right)$, denoted as $\epsilon_{r, t} \sim$ i.i.d. $\left(0, \sigma_{r}^{2}\right)$, which has the usual interpretation of an exogenous monetary policy shock.

\section{EMPIRICAL INVESTIGATION}

The first question we would like to ask is the following: do these flexible inflationtargeting central banks place much weight on exchange rate deviations? Existing papers have focused on whether and how much central banks respond to exchange rates at the behavioral level of reduced form interest-rate rules (see Lubik and Schorfheide 2007, Justiniano and Preston Forthcoming). The second question is whether the preferences of the central banks are "different" or "similar." We address these empirical questions using Bayesian empirical methods on the model structure we have. 
TABLE 1

Prior Parameter Densities for All Models

\begin{tabular}{lccccc}
\hline \hline & Prior mean & $2.5 \%$ & $97.5 \%$ & Domain & Density function \\
\hline$h$ & 0.60 & 0.19 & 0.93 & $(0,1)$ & Beta \\
$\sigma$ & 1.00 & 0.27 & 2.19 & $\mathbb{R}_{+}$ & Gamma \\
$\phi$ & 1.50 & 1.01 & 1.99 & $\mathbb{R}_{+}$ & Gamma \\
$\eta$ & 1.00 & 0.27 & 2.19 & $\mathbb{R}_{+}$ & Gamma \\
$\delta_{H}$ & 0.70 & 0.25 & 0.98 & $(0,1)$ & Beta \\
$\delta_{F}$ & 0.70 & 0.25 & 0.98 & $(0,1)$ & Beta \\
$\theta_{H}$ & 0.50 & 0.13 & 0.87 & $(0,1)$ & Beta \\
$\theta_{F}$ & 0.50 & 0.13 & 0.87 & $(0,1)$ & Beta \\
$a_{1}$ & 0.50 & 0.19 & 0.96 & $(0,1)$ & Beta \\
$b_{2}$ & 0.50 & 0.19 & 0.96 & $(0,1)$ & Beta \\
$c_{3}$ & 0.50 & 0.19 & 0.96 & $(0,1)$ & Beta \\
$\rho_{a}$ & 0.50 & 0.13 & 0.87 & $(0,1)$ & Beta \\
$\rho_{q}$ & 0.90 & 0.23 & 1.00 & $(0,1)$ & Beta \\
$\rho_{s}$ & 0.25 & 0.01 & 0.72 & $(0,1)$ & Beta \\
$\mu_{q}$ & 0.50 & 0.13 & 1.07 & $\mathbb{R}_{+}$ & Gamma \\
$\mu_{y}$ & 0.50 & 0.09 & 1.24 & $\mathbb{R}_{+}$ & Gamma \\
$\mu_{r}$ & 0.50 & 0.09 & 1.24 & $\mathbb{R}_{+}$ & Gamma \\
$\sigma_{H}$ & 2.66 & 0.91 & 7.32 & $\mathbb{R}_{+}$ & Inverse Gamma \\
$\sigma_{F}$ & 2.67 & 0.91 & 7.33 & $\mathbb{R}_{+}$ & Inverse Gamma \\
$\sigma_{a}$ & 1.19 & 0.52 & 2.66 & $\mathbb{R}_{+}$ & Inverse Gamma \\
$\sigma_{q}$ & 0.53 & 0.32 & 0.87 & $\mathbb{R}_{+}$ & Inverse Gamma \\
$\sigma_{s}$ & 1.19 & 0.52 & 2.66 & $\mathbb{R}_{+}$ & Inverse Gamma \\
$\sigma_{\pi^{*}}$ & 1.19 & 0.52 & 2.66 & $\mathbb{R}_{+}$ & Inverse Gamma \\
$\sigma_{y^{*}}$ & 1.19 & 0.52 & 2.66 & $\mathbb{R}_{+}$ & Inverse Gamma \\
$\sigma_{r^{*}}$ & 1.19 & 0.52 & 2.66 & $\mathbb{R}_{+}$ & Inverse Gamma \\
$\sigma_{r}$ & 1.19 & 0.52 & 2.66 & $\mathbb{R}_{+}$ & Inverse Gamma \\
\hline
\end{tabular}

Note: For $\mu_{q}=0$ the prior and posterior distributions will be degenerate at zero.

\subsection{Estimation Strategy}

We are interested in estimating the structural or deep parameters of our model and variations of it. We classify a candidate model $M$ by its list of parameters, $\Theta$. We proceed by estimating two versions of the model for each country. The first version utilizes the general one-period loss specification in (44). We will call this larger model $M_{1}$ in subsequent discussions.

The set of parameters to be estimated are the following central back preference parameters, $\left\{\mu_{y}, \mu_{r}, \mu_{q}\right\}$, the private sector deep parameters, $\{h, \sigma, \phi$, $\left.\eta, \delta_{H}, \delta_{F}, \theta_{H}, \theta_{F}\right\}$ and the parameters for exogenous processes $\left\{a_{1}, b_{2}, c_{3}, \rho_{a}\right.$, $\left.\rho_{q}, \rho_{s}, \sigma_{H}, \sigma_{F}, \sigma_{a}, \sigma_{q}, \sigma_{s}, \sigma_{\pi^{*}}, \sigma_{y^{*}}, \sigma_{r^{*}}, \sigma_{r}\right\} .^{4}$

The second version, which we shall denote as model $M_{2}$, uses (44) but restricting $\mu_{q}=0$. We can then address the first question by using Bayesian posterior odds comparisons to see if a model with or without $\mu_{q}=0$ is more probable, all other things equal.

Our estimation procedure uses the random-walk Metropolis Markov chain Monte Carlo (MCMC) method. We outline this popular algorithm in Appendix B. Table 1

4. There is very little information in the data to help us pin down the discount factor $\beta$ and imports share in domestic consumption, $\alpha$, so we set these as 0.99 and 0.45 , respectively. 
summarizes the prior marginal density functions we use on each estimated parameter in the models. We use fairly agnostic or dispersed prior densities as evident in the wide $95 \%$ confidence intervals around the prior means. ${ }^{5}$ To ensure that theoretical restrictions on the parameter space are satisfied, we draw from prior densities that are restricted to the appropriate supports. For example, we define a prior density for the Calvo parameter $\theta_{H}$ to have the domain $(0,1)$.

For each candidate $\Theta$, the linear rational expectations (RE) system including the optimal monetary policy problem is solved to obtain an affine solution, $\{\mathbf{A}(\Theta)$, $\mathbf{C}(\Theta)\}$, in terms of the endogenous state variables $y_{t}$ and the central-bank policy decision variables, $x_{t}$ (which is just the scalar $r_{t}$ in our case)

$$
\xi_{t+1}=\mathbf{A}(\Theta) \xi_{t}+\mathbf{C}(\Theta) \varepsilon_{t+1},
$$

where $\xi_{t}:=\left(y_{t}, x_{t}\right)$. We can map some of the variables in $\xi_{t}$ to a vector of observable variables, $y_{t}^{o}$ using an observation equation

$$
y_{t}^{o}=\mathbf{G} \xi_{t} .
$$

We set the length of the parameters' Markov chain to be $N=2 \times 10^{6}$ draws and remove the first half of the sample (the "burn-in" period) to remove any effect of the initial condition of the Markov chain $\left\{\Theta_{n}\right\}_{n \in \mathbb{N}}$ and also perform some diagnostic tests to check that our MCMC procedure has converged to its stable, invariant distribution.

\subsection{Data}

Each model we consider has nine structural shocks. To avoid stochastic singularity, we match these to nine observable time series for each of our sample countries: Australia, Canada, and New Zealand. We use quarterly data over the period 1990Q12005Q3. ${ }^{6}$ The time series data are from the International Monetary Fund's (IMF) International Financial Statistics database, with the exception of Australian and New Zealand CPI inflation series, which were obtained from the RBA and the Reserve Bank of New Zealand, respectively. The data we collect (with their corresponding theoretical counterparts in parentheses) are import price inflation in home currency as a proxy for foreign goods inflation $\left(\pi_{F, t}:=p_{F, t}-p_{F, t-1}\right)$, home-U.S. real exchange rate $\left(q_{t}\right)$, the "terms of trade" constructed as the ratio of import prices to export prices $\left(s_{t}:=p_{F, t}-p_{H, t}\right)$, home real GDP $\left(y_{t}\right)$, home CPI inflation $\left(\pi_{t}\right)$, home nominal

5. We have also conducted alternative MCMC simulations based on competing prior density specifications. Our reported results are generally robust to these prior specifications. These less interesting results are not reported in the paper.

6. The Reserve Bank of New Zealand officially began targeting inflation in February 1990 and Canada followed 1 year later. The RBA suggests that inflation targeting was officially adopted in the first half of 1993. However, Bernanke et al. (1999) note that Australian interest rates rose dramatically in the late 1980s with no noticeable increase in inflation and conclude the RBA possessed objectives for inflation that predate the announced adoption of inflation targeting. Since we seek to define preferences via the underlying interest rate rule, we define the inflation targeting period in Australia as beginning slightly earlier than some other commentators. 
(overnight cash) interest rate $\left(r_{t}\right)$, the U.S. CPI inflation rate from FRED $\left(\pi_{t}^{*}\right)$, U.S. output $\left(y_{t}^{*}\right)$, and the U.S. federal funds rate $\left(r_{t}^{*}\right)$.

We detrend using the Hodrick-Prescott and construct an output gap of deviations of output from this trend. We use the Hodrick-Prescott filter because we pursue a positive rather than a normative description of policy objectives and over our sample period, monetary policy has been driven by an output gap methodology. This is true of Australia (see the small Australian model described in Beechey et al. 2000), Canada (in particular, the Quarterly Projection Model, described in Coletti et al. 1996), and New Zealand (see the New Zealand's core policy model, the Forecasting and Policy System, detailed in Black et al. 1997, and for a more recent description of the role of the output gap in policy, Hargreaves, Kite, and Hodgetts 2006). Over the latter part of our sample, output gaps filtered with a multivariate filter have been used, although these measures are not quantitatively dissimilar (see, e.g., Hargreaves, Kite, and Hodgetts 2006). We also filter the terms of trade and real exchange rate data using the HP filter for similar reasons. As robustness checks, we have repeated the reported exercises using an alternative detrending method. The main conclusions from our model comparison exercises do not change.

\section{RESULTS}

Before we turn to addressing our first empirical question of whether the central banks in question care explicitly about the exchange rate, we will discuss the estimates of parameters in the models themselves and show that the estimates are quite plausible economically. In Section 3.2, we take up the first main question. In Section 3.3, we repeat the same exercise under an alternative data detrending assumption, to ensure that our result is robust to this assumption. In Section 3.4, we will address the second question of whether these central banks are similar in their policy preferences. Finally, in Section 4 we highlight the implications of our policy-preferences analysis for reduced-form behavioral policy responses and also compare the result with estimations of a class of Lubik and Schorfheide (2007)-type ad hoc simple rules.

\subsection{Structural Parameter Estimates}

The estimated prior and posterior density functions on the key structural model parameters for Australia, Canada, and New Zealand are displayed in Figures 1-3. Mean estimates, standard deviations, and 95\% confidence intervals for the posterior estimates are reported in Tables 2-7.

In addition, the tables report summaries of diagnostic tests for convergence of the Markov chains of the parameters. The convergence test statistics were computed by taking a subsequence of the total 2 million draws, with a length of 0.5 million draws, to reduce computational burden. The NSE in the fifth column refers to the numeric standard error as an approximation to the true posterior standard error described in Geweke (1999). The $p$-values in the sixth column refer to the equality test between the 

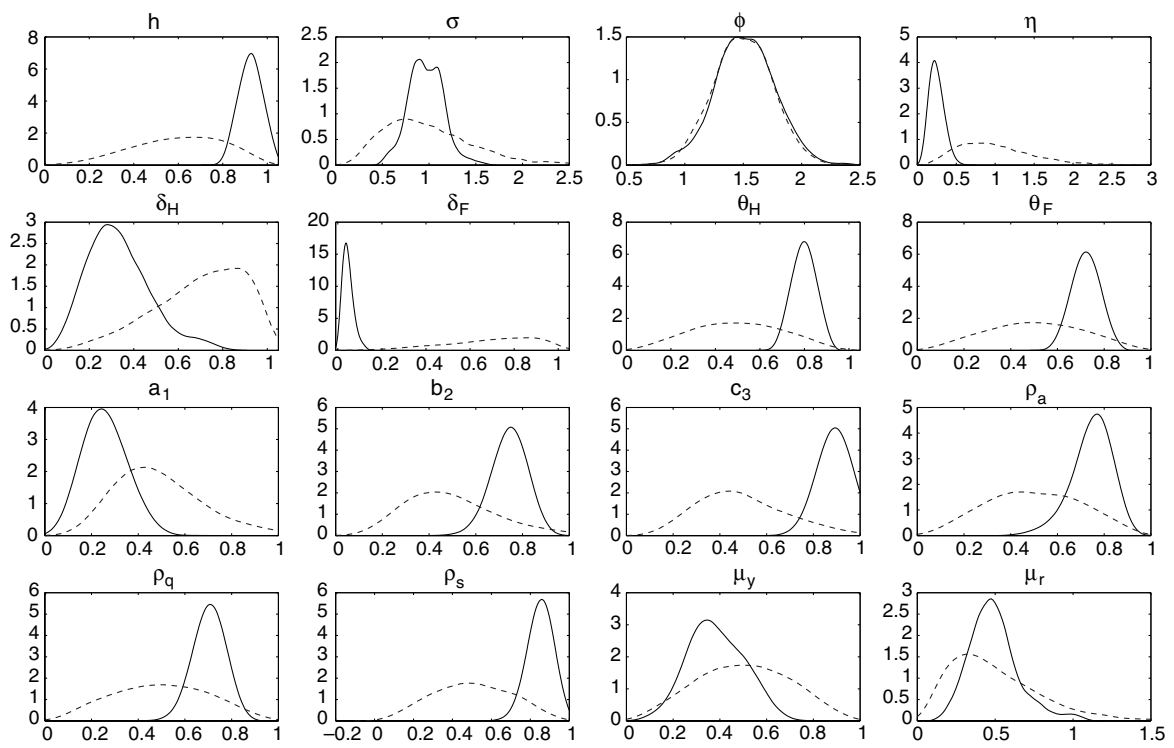

FIG. 1. Posterior Distribution of Key Parameters: Australia. Prior (dashed) and Posterior (solid).
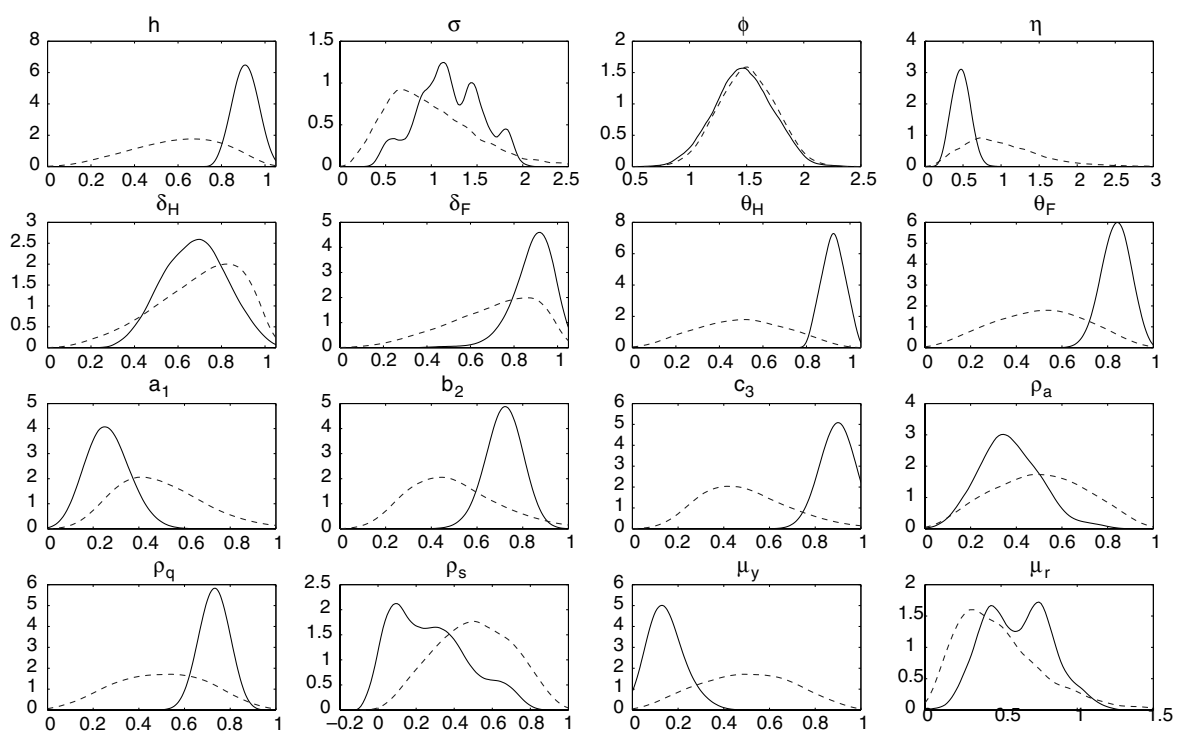

FIG. 2. Posterior Distribution of Key Parameters: Canada. Prior (dashed) and Posterior (solid). 

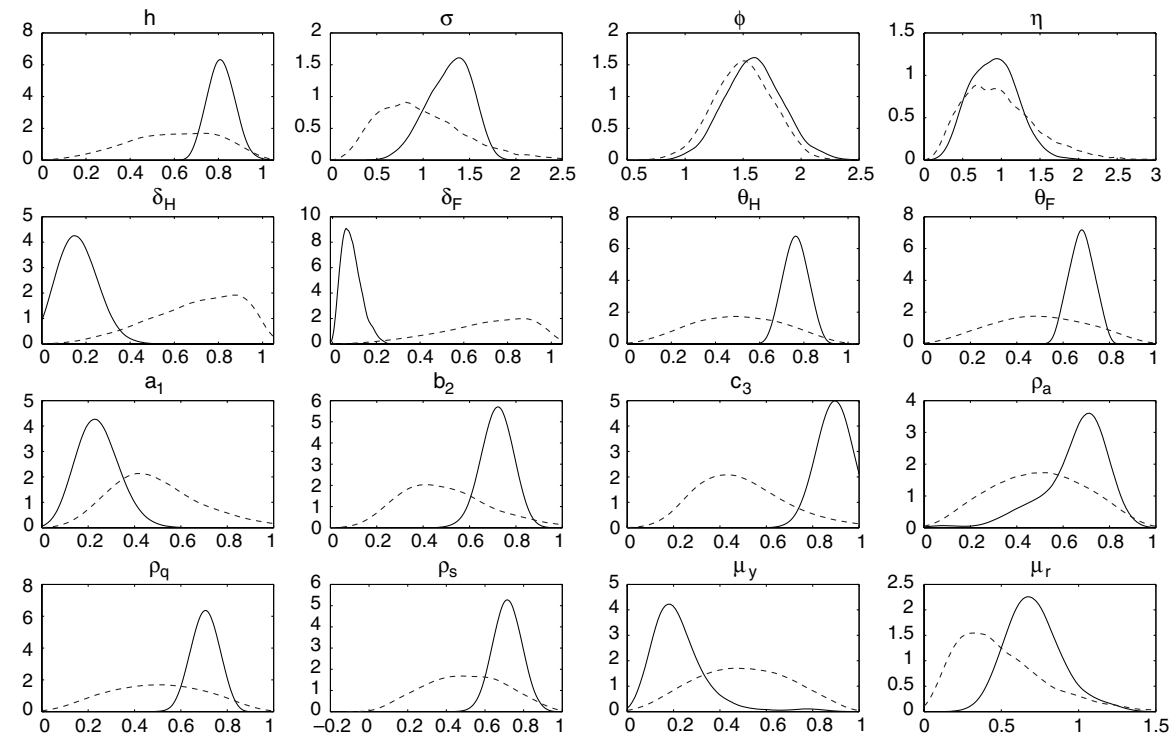

FIG. 3. Posterior Distribution of Key Parameters: New Zealand. Prior (dashed) and Posterior (solid).

means calculated using the first and second half of the chain. In each of the models, there are only one or two parameters that did not satisfy the equality test at the $5 \%$ level. None of the test statistics are significant at the $1 \%$ level and there is no obvious pattern to which coefficients fail the equality test.

The seventh column shows the univariate "shrink factors" using the ratio of between- and within-chain variances as in Brooks and Gelman (1998). A shrink factor close to 1 is evidence of convergence to a stationary distribution. Almost all of the shrink factors were less than 1.1 and the maximum value across the six models is 1.26. The parameters with a shrink factor greater than 1.1 are those parameters that did not satisfy $5 \%$ equality test. Overall, the evidence suggests that the Markov chains have converged to their stationary distribution.

Australia. The marginal posterior density estimates for the key parameters for Australia are displayed in Figure 1 for the case where the central bank is restricted to put no weight on exchange rate variability.

The full set of model estimates is reported in Table 2 for model $M_{1}$ and Table 3 for model $M_{2}$. Our posterior mean estimates of the Calvo-type frequency of price changes are $\hat{\theta}_{H} \approx 0.77$ for $M_{1}$ and $\hat{\theta}_{H} \approx 0.8$ for $M_{2}$, and, $\hat{\theta}_{F} \approx 0.68$ for $M_{1}$ and $\hat{\theta}_{F} \approx 0.72$ for $M_{2}$, respectively, in the home goods and imported goods sectors. This suggests that in the home goods sector, the average duration that prices remain fixed is between 4.3 and 5 quarters across the two models. Similarly, for the imported goods sector, average prices stay the same for 3-3.6 quarters on average. The "backward lookingness" in the Phillips curves, represented by $\delta_{H}$ and $\delta_{F}$, is quite low, especially, for the 
TABLE 2

Posterior Parameters and Convergence Diagnostics: Australia $\left(\mu_{q} \neq 0\right)$

\begin{tabular}{lccccccc}
\hline \hline & Post mean & Post std & $2.5 \%$ & $97.5 \%$ & NSE & $p$-value & B-G \\
\hline$\beta$ & 0.990 & 0.000 & 0.990 & 0.990 & 0.000 & 1.000 & 1.000 \\
$\alpha$ & 0.450 & 0.000 & 0.450 & 0.450 & 0.000 & 1.000 & 1.000 \\
$h$ & 0.917 & 0.022 & 0.871 & 0.953 & 0.002 & 0.234 & 1.029 \\
$\sigma$ & 0.809 & 0.259 & 0.395 & 1.440 & 0.045 & 0.464 & 1.026 \\
$\phi$ & 1.586 & 0.245 & 1.111 & 2.059 & 0.011 & 0.993 & 1.000 \\
$\eta$ & 0.363 & 0.101 & 0.210 & 0.594 & 0.012 & 0.351 & 1.021 \\
$\delta_{H}$ & 0.257 & 0.101 & 0.096 & 0.504 & 0.013 & 0.353 & 1.023 \\
$\delta_{F}$ & 0.046 & 0.027 & 0.010 & 0.109 & 0.001 & 0.651 & 1.001 \\
$\theta_{H}$ & 0.777 & 0.026 & 0.726 & 0.829 & 0.003 & 0.666 & 1.004 \\
$\theta_{F}$ & 0.682 & 0.036 & 0.612 & 0.754 & 0.004 & 0.951 & 1.000 \\
$a_{1}$ & 0.259 & 0.084 & 0.113 & 0.439 & 0.002 & 0.041 & 1.003 \\
$b_{2}$ & 0.719 & 0.061 & 0.583 & 0.822 & 0.003 & 0.955 & 1.000 \\
$c_{3}$ & 0.891 & 0.059 & 0.770 & 1.005 & 0.001 & 0.258 & 1.001 \\
$\rho_{a}$ & 0.809 & 0.035 & 0.735 & 0.870 & 0.002 & 0.657 & 1.001 \\
$\rho_{q}$ & 0.684 & 0.050 & 0.576 & 0.773 & 0.004 & 0.832 & 1.000 \\
$\rho_{s}$ & 0.811 & 0.049 & 0.696 & 0.893 & 0.004 & 0.830 & 1.001 \\
$\mu_{q}$ & 0.005 & 0.003 & 0.001 & 0.012 & 0.000 & 0.729 & 1.001 \\
$\mu_{y}$ & 0.412 & 0.156 & 0.165 & 0.766 & 0.021 & 0.759 & 1.003 \\
$\mu_{r}$ & 0.611 & 0.186 & 0.307 & 0.988 & 0.028 & 0.198 & 1.062 \\
$\sigma_{H}$ & 1.057 & 0.317 & 0.565 & 1.827 & 0.031 & 0.576 & 1.005 \\
$\sigma_{F}$ & 4.430 & 1.629 & 1.393 & 7.121 & 0.288 & 0.517 & 1.021 \\
$\sigma_{a}$ & 5.178 & 1.021 & 3.395 & 7.325 & 0.162 & 0.154 & 1.079 \\
$\sigma_{q}$ & 0.746 & 0.123 & 0.542 & 1.023 & 0.009 & 0.736 & 1.001 \\
$\sigma_{s}$ & 5.452 & 0.543 & 4.494 & 6.515 & 0.061 & 0.061 & 1.066 \\
$\sigma_{\pi^{*}}$ & 0.418 & 0.043 & 0.341 & 0.509 & 0.001 & 0.435 & 1.000 \\
$\sigma_{y^{*}}$ & 0.547 & 0.071 & 0.421 & 0.701 & 0.002 & 0.888 & 1.000 \\
$\sigma_{r^{*}}$ & 0.220 & 0.021 & 0.182 & 0.265 & 0.000 & 0.954 & 1.000 \\
$\sigma_{r}$ & 0.363 & 0.051 & 0.273 & 0.471 & 0.002 & 0.111 & 1.004 \\
\hline & & & & & & & \\
\hline & & & & & & &
\end{tabular}

Notes: The numerical standard error (NSE) as given in Geweke (1999). The $p$-value is computed using $L=0.08$ in Geweke (1999). The B-G univariate "shrink factor" as in Brooks and Gelman (1998).

imported goods sector. The high degrees of price stickiness imply that inflation is not very sensitive to changes in marginal cost (or LOP gap) movements, and therefore, a smaller and slower transmission of monetary policy to inflation.

In contrast, consumption is very sensitive to real interest rate changes because the estimate of $\sigma$, the coefficient of relative risk aversion, is quite close to 1 . The degree of habit persistence is quite high, $\hat{h} \approx 0.9$. This has the opposite effect on the sensitivity of consumption to real-interest-rate changes. The uniform within-sector demand elasticity of substitution estimate is $\hat{\eta} \approx 0.36\left(M_{1}\right)$ or $\hat{\eta} \approx 0.17\left(M_{2}\right)$. This is lower than typical calibrations. For example, Monacelli (2005) sets $\eta \approx 1$.6. A low $\eta$ implies $\pi_{H}$ or domestic output gap is not very sensitive to terms of trade movements compared to usual calibrations, all else equal. The inverse labor supply elasticity is $\hat{\phi} \approx 1.5$.

Canada. The marginal posterior density estimates for the key parameters for Canada are displayed in Figure 2. The full set of model estimates is reported in Table 4 for model $M_{1}$ and in Table 5 for model $M_{2}$. 
TABLE 3

Posterior Parameters and Convergence Diagnostics: Australia $\left(\mu_{q}=0\right)$

\begin{tabular}{|c|c|c|c|c|c|c|c|}
\hline & Post mean & Post std & $2.5 \%$ & $97.5 \%$ & NSE & $p$-value & B-G \\
\hline$\beta$ & 0.990 & 0.000 & 0.990 & 0.990 & 0.000 & 1.000 & 1.000 \\
\hline$\alpha$ & 0.450 & 0.000 & 0.450 & 0.450 & 0.000 & 1.000 & 1.000 \\
\hline$h$ & 0.925 & 0.022 & 0.876 & 0.963 & 0.003 & 0.899 & 1.000 \\
\hline$\sigma$ & 1.029 & 0.241 & 0.661 & 1.646 & 0.036 & 0.014 & 1.244 \\
\hline$\phi$ & 1.492 & 0.261 & 0.968 & 1.995 & 0.016 & 0.172 & 1.011 \\
\hline$\eta$ & 0.219 & 0.097 & 0.079 & 0.430 & 0.014 & 0.008 & 1.231 \\
\hline$\delta_{H}$ & 0.399 & 0.162 & 0.142 & 0.717 & 0.021 & 0.000 & 1.382 \\
\hline$\delta_{F}$ & 0.047 & 0.025 & 0.010 & 0.108 & 0.001 & 0.436 & 1.002 \\
\hline$\theta_{H}$ & 0.797 & 0.026 & 0.743 & 0.845 & 0.003 & 0.824 & 1.001 \\
\hline$\theta_{F}$ & 0.720 & 0.035 & 0.649 & 0.785 & 0.005 & 0.701 & 1.004 \\
\hline$a_{1}$ & 0.257 & 0.084 & 0.110 & 0.433 & 0.002 & 0.984 & 1.000 \\
\hline$b_{2}$ & 0.750 & 0.063 & 0.617 & 0.861 & 0.005 & 0.144 & 1.022 \\
\hline$c_{3}$ & 0.891 & 0.060 & 0.772 & 1.007 & 0.001 & 0.621 & 1.000 \\
\hline$\rho_{a}$ & 0.728 & 0.101 & 0.465 & 0.847 & 0.013 & 0.019 & 1.197 \\
\hline$\rho_{q}$ & 0.703 & 0.049 & 0.602 & 0.796 & 0.004 & 0.719 & 1.001 \\
\hline$\rho_{s}$ & 0.852 & 0.048 & 0.737 & 0.927 & 0.006 & 0.870 & 1.001 \\
\hline$\mu_{y}$ & 0.404 & 0.354 & 0.202 & 1.482 & 0.021 & 0.000 & 1.697 \\
\hline$\mu_{r}$ & 0.517 & 0.153 & 0.265 & 0.845 & 0.022 & 0.287 & 1.035 \\
\hline$\sigma_{H}$ & 2.058 & 0.994 & 0.728 & 4.223 & 0.167 & 0.137 & 1.098 \\
\hline$\sigma_{F}$ & 1.504 & 1.290 & 0.355 & 5.405 & 0.168 & 0.227 & 1.063 \\
\hline$\sigma_{a}$ & 6.758 & 1.105 & 4.692 & 8.891 & 0.167 & 0.006 & 1.280 \\
\hline$\sigma_{q}$ & 0.819 & 0.121 & 0.602 & 1.069 & 0.009 & 0.130 & 1.022 \\
\hline$\sigma_{s}$ & 5.716 & 0.661 & 4.388 & 7.167 & 0.086 & 0.013 & 1.162 \\
\hline$\sigma_{\pi^{*}}$ & 0.419 & 0.043 & 0.341 & 0.509 & 0.001 & 0.651 & 1.000 \\
\hline$\sigma_{y^{*}}$ & 0.533 & 0.071 & 0.410 & 0.686 & 0.002 & 0.411 & 1.001 \\
\hline$\sigma_{r^{*}}$ & 0.219 & 0.021 & 0.182 & 0.265 & 0.000 & 0.866 & 1.000 \\
\hline$\sigma_{r}$ & 0.342 & 0.042 & 0.267 & 0.430 & 0.001 & 0.986 & 1.000 \\
\hline
\end{tabular}

Notes: The numerical standard error (NSE) as given in Geweke (1999). The $p$-value is computed using $L=0.08$ in Geweke (1999). The B-G univariate "shrink factor" as in Brooks and Gelman (1998).

Notable exceptions for Canada's results are that the degrees of backward-looking behavior in firms' pricing are much higher than the estimates for Australia. Here we have $\delta_{H}$ and $\delta_{F}$ estimated in the order of 0.65 and 0.8 respectively.

New Zealand. The marginal posterior density estimates for the key parameters for New Zealand are displayed in Figure 3 for the case where $\mu_{q}=0$. The full set of model estimates are reported in Table 6 for model $M_{1}$ and Table 7 for model $M_{2}$.

The private sector deep parameters in New Zealand are quite similar to Australia with the notable exception that the uniform within-sector demand elasticity of substitution estimate of $\hat{\eta} \approx 1$ is much higher than in Australia or Canada. This implies a greater elasticity of substitution of consumption between home and foreign goods in the model. It also implies that New Zealand's output gap will be very responsive to terms of trade movements.

\subsection{Are the Central Banks Concerned about "Exchange Rate Volatility"?}

Our first empirical question asks whether these flexible inflation-targeting central banks care about the real exchange rate explicitly. Consider two competing models 
TABLE 4

Posterior Parameters and Convergence Diagnostics: Canada $\left(\mu_{q} \neq 0\right)$

\begin{tabular}{|c|c|c|c|c|c|c|c|}
\hline & Post mean & Post std & $2.5 \%$ & $97.5 \%$ & NSE & $p$-value & B-G \\
\hline$\beta$ & 0.990 & 0.000 & 0.990 & 0.990 & 0.000 & 1.000 & 1.000 \\
\hline$\alpha$ & 0.450 & 0.000 & 0.450 & 0.450 & 0.000 & 1.000 & 1.000 \\
\hline$h$ & 0.912 & 0.030 & 0.850 & 0.966 & 0.003 & 0.415 & 1.010 \\
\hline$\sigma$ & 1.241 & 0.354 & 0.557 & 1.875 & 0.061 & 0.409 & 1.032 \\
\hline$\phi$ & 1.477 & 0.248 & 1.009 & 1.976 & 0.006 & 0.057 & 1.004 \\
\hline$\eta$ & 0.416 & 0.119 & 0.206 & 0.668 & 0.010 & 0.443 & 1.009 \\
\hline$\delta_{H}$ & 0.644 & 0.179 & 0.227 & 0.937 & 0.024 & 0.221 & 1.050 \\
\hline$\delta_{F}$ & 0.776 & 0.145 & 0.423 & 0.977 & 0.020 & 0.546 & 1.012 \\
\hline$\theta_{H}$ & 0.933 & 0.017 & 0.901 & 0.966 & 0.002 & 0.099 & 1.060 \\
\hline$\theta_{F}$ & 0.849 & 0.031 & 0.785 & 0.907 & 0.002 & 0.407 & 1.006 \\
\hline$a_{1}$ & 0.266 & 0.084 & 0.119 & 0.442 & 0.002 & 0.976 & 1.000 \\
\hline$b_{2}$ & 0.748 & 0.064 & 0.611 & 0.865 & 0.003 & 0.706 & 1.000 \\
\hline$c_{3}$ & 0.893 & 0.061 & 0.770 & 1.009 & 0.001 & 0.566 & 1.000 \\
\hline$\rho_{a}$ & 0.433 & 0.151 & 0.144 & 0.723 & 0.022 & 0.522 & 1.013 \\
\hline$\rho_{q}$ & 0.704 & 0.048 & 0.607 & 0.795 & 0.004 & 0.852 & 1.000 \\
\hline$\rho_{s}$ & 0.229 & 0.167 & 0.011 & 0.607 & 0.024 & 0.122 & 1.077 \\
\hline$\mu_{q}$ & 0.007 & 0.003 & 0.002 & 0.015 & 0.000 & 0.511 & 1.002 \\
\hline$\mu_{y}$ & 0.157 & 0.094 & 0.033 & 0.409 & 0.012 & 0.891 & 1.000 \\
\hline$\mu_{r}$ & 0.855 & 0.424 & 0.186 & 1.779 & 0.068 & 0.014 & 1.266 \\
\hline$\sigma_{H}$ & 20.646 & 1.569 & 18.025 & 24.428 & 0.243 & 0.270 & 1.053 \\
\hline$\sigma_{F}$ & 0.752 & 0.411 & 0.287 & 1.869 & 0.036 & 0.431 & 1.008 \\
\hline$\sigma_{a}$ & 2.121 & 1.004 & 0.584 & 4.539 & 0.144 & 0.590 & 1.009 \\
\hline$\sigma_{q}$ & 0.841 & 0.111 & 0.640 & 1.077 & 0.008 & 0.659 & 1.001 \\
\hline$\sigma_{s}^{q}$ & 2.271 & 0.369 & 1.584 & 3.014 & 0.035 & 0.296 & 1.017 \\
\hline$\sigma_{\pi^{*}}$ & 0.367 & 0.040 & 0.296 & 0.452 & 0.000 & 0.964 & 1.000 \\
\hline$\sigma_{y^{*}}$ & 0.533 & 0.071 & 0.406 & 0.687 & 0.002 & 0.651 & 1.000 \\
\hline$\sigma_{r^{*}}$ & 0.222 & 0.022 & 0.183 & 0.269 & 0.000 & 0.102 & 1.000 \\
\hline$\sigma_{r}$ & 0.360 & 0.045 & 0.281 & 0.457 & 0.001 & 0.726 & 1.000 \\
\hline
\end{tabular}

Notes: The numerical standard error (NSE) as given in Geweke (1999). The $p$-value is computed using $L=0.08$ in Geweke (1999). The B-G univariate "shrink factor" as in Brooks and Gelman (1998).

of central banks for a data set $y$. Denote a flexible inflation targeter with one-period payoff summarized by (44) as $M_{1}:=\left\{\Theta: 0<\mu_{q} \in \Theta\right\}$. Let the alternative central bank that does not target exchange rate deviations be given by $M_{2}:=\{\Theta: 0=$ $\left.\mu_{q} \in \Theta\right\}$.

Table 8 summarizes our model comparison based on the posterior odds ratio or Bayes factor, which in our case, is the ratio of the marginal likelihoods of the two competing models. The marginal likelihood of each model for a given data set is numerically computed using the modified harmonic mean estimator in Geweke (1999). For each of the three countries, there is a "better fit" of the data for model $M_{2}$ than $M_{1}$. For example, consider Canada, which has the lowest Bayes factor of $2.97 \times 10^{4}$ across the three economies. In order to infer that the Bank of Canada explicitly targets exchange rate volatility $\left(M_{1}\right)$, one would need to have a prior belief on $M_{1}$ which is 2,970 times stronger than one's prior belief on $M_{2}$. Our result in favor of $M_{2}$ is corroborated by the observation that the posterior densities of $\mu_{q}$, in the case of model $M_{1}$, estimated for all three countries is very tightly centered around a positive number close to zero. Our result suggests that these small open economy inflation targeters do not explicitly target exchange rate fluctuations via its interest rate decisions. 
TABLE 5

Posterior Parameters and Convergence Diagnostics: Canada $\left(\mu_{q}=0\right)$

\begin{tabular}{|c|c|c|c|c|c|c|c|}
\hline & Post mean & Post std & $2.5 \%$ & $97.5 \%$ & NSE & $p$-value & B-G \\
\hline$\beta$ & 0.990 & 0.000 & 0.990 & 0.990 & 0.000 & 1.000 & 1.000 \\
\hline$\alpha$ & 0.450 & 0.000 & 0.450 & 0.450 & 0.000 & 1.000 & 1.000 \\
\hline$h$ & 0.906 & 0.030 & 0.851 & 0.964 & 0.003 & 0.290 & 1.015 \\
\hline$\sigma$ & 1.285 & 0.338 & 0.578 & 1.875 & 0.055 & 0.175 & 1.075 \\
\hline$\phi$ & 1.456 & 0.254 & 0.961 & 1.952 & 0.006 & 0.036 & 1.004 \\
\hline$\eta$ & 0.476 & 0.114 & 0.268 & 0.704 & 0.009 & 0.812 & 1.001 \\
\hline$\delta_{H}$ & 0.657 & 0.177 & 0.237 & 0.929 & 0.023 & 0.129 & 1.084 \\
\hline$\delta_{F}$ & 0.873 & 0.082 & 0.684 & 0.989 & 0.007 & 0.146 & 1.026 \\
\hline$\theta_{H}$ & 0.922 & 0.016 & 0.891 & 0.952 & 0.001 & 0.367 & 1.009 \\
\hline$\theta_{F}$ & 0.852 & 0.037 & 0.760 & 0.905 & 0.003 & 0.039 & 1.088 \\
\hline$a_{1}$ & 0.265 & 0.084 & 0.119 & 0.443 & 0.001 & 0.670 & 1.000 \\
\hline$b_{2}$ & 0.718 & 0.066 & 0.578 & 0.840 & 0.003 & 0.552 & 1.001 \\
\hline$c_{3}$ & 0.897 & 0.059 & 0.775 & 1.011 & 0.001 & 0.897 & 1.000 \\
\hline$\rho_{a}$ & 0.366 & 0.137 & 0.120 & 0.639 & 0.016 & 0.530 & 1.009 \\
\hline$\rho_{q}$ & 0.731 & 0.044 & 0.640 & 0.812 & 0.003 & 0.720 & 1.001 \\
\hline$\rho_{s}$ & 0.257 & 0.180 & 0.012 & 0.658 & 0.025 & 0.583 & 1.009 \\
\hline$\mu_{y}$ & 0.147 & 0.069 & 0.049 & 0.313 & 0.006 & 0.941 & 1.000 \\
\hline$\mu_{r}$ & 0.672 & 0.233 & 0.248 & 1.106 & 0.033 & 0.061 & 1.110 \\
\hline$\sigma_{H}$ & 20.462 & 3.145 & 13.842 & 24.834 & 0.545 & 0.214 & 1.081 \\
\hline$\sigma_{F}$ & 0.682 & 0.490 & 0.277 & 2.347 & 0.033 & 0.197 & 1.036 \\
\hline$\sigma_{a}$ & 2.397 & 1.618 & 0.774 & 6.779 & 0.221 & 0.169 & 1.085 \\
\hline$\sigma_{q}$ & 0.780 & 0.104 & 0.600 & 1.004 & 0.004 & 0.568 & 1.001 \\
\hline$\sigma_{s}^{q}$ & 2.154 & 0.362 & 1.448 & 2.856 & 0.039 & 0.712 & 1.002 \\
\hline$\sigma_{\pi^{*}}$ & 0.368 & 0.040 & 0.297 & 0.453 & 0.000 & 0.755 & 1.000 \\
\hline$\sigma_{y^{*}}$ & 0.546 & 0.073 & 0.419 & 0.704 & 0.001 & 0.073 & 1.002 \\
\hline$\sigma_{r^{*}}$ & 0.220 & 0.021 & 0.183 & 0.266 & 0.000 & 0.409 & 1.000 \\
\hline$\sigma_{r}$ & 0.315 & 0.035 & 0.252 & 0.389 & 0.001 & 0.787 & 1.000 \\
\hline
\end{tabular}

Notes: The numerical standard error (NSE) as given in Geweke (1999). The $p$-value is computed using $L=0.08$ in Geweke (1999). The B-G univariate "shrink factor" as in Brooks and Gelman (1998).

\subsection{Robustness of Result}

We also ensure that the previous model comparison result is not an artifact of our data detrending assumption. We report an alternative set of results, summarized in Table 9, which assumes that the cyclical components of output gap, the terms of trade, real exchange rate, and consumption are constructed by removing a linear trend from each series. For each of the three countries, there is a "better fit" of the data for model $M_{2}$ than $M_{1}$.

\subsection{Central Banks' Objectives and Similarities}

In this section, we address the second empirical question of what are the features of these central banks' preferences and whether they are similar in a statistical sense. More precisely, we will be looking at the "degree of overlap" between the marginal posterior distributions, and also the joint posterior distributions, on their preference parameters.

Inspection of the results displayed in Tables 2-8 reveals that the following features drive central bank objectives in Australia, Canada, and New Zealand. First, these 
TABLE 6

Posterior Parameters and Convergence Diagnostics: New Zealand $\left(\mu_{q} \neq 0\right)$

\begin{tabular}{|c|c|c|c|c|c|c|c|}
\hline & Post mean & Post std & $2.5 \%$ & $97.5 \%$ & NSE & $p$-value & B-G \\
\hline$\beta$ & 0.990 & 0.000 & 0.990 & 0.990 & 0.000 & 1.000 & 1.000 \\
\hline$\alpha$ & 0.450 & 0.000 & 0.450 & 0.450 & 0.000 & 1.000 & 1.000 \\
\hline$h$ & 0.785 & 0.040 & 0.729 & 0.896 & 0.004 & 0.195 & 1.060 \\
\hline$\sigma$ & 1.568 & 0.396 & 0.822 & 2.257 & 0.070 & 0.186 & 1.085 \\
\hline$\phi$ & 1.550 & 0.247 & 1.053 & 2.028 & 0.013 & 0.654 & 1.001 \\
\hline$\eta$ & 1.011 & 0.329 & 0.421 & 1.683 & 0.041 & 0.805 & 1.001 \\
\hline$\delta_{H}$ & 0.175 & 0.074 & 0.055 & 0.338 & 0.006 & 0.761 & 1.001 \\
\hline$\delta_{F}$ & 0.087 & 0.045 & 0.020 & 0.193 & 0.003 & 0.483 & 1.003 \\
\hline$\theta_{H}$ & 0.775 & 0.029 & 0.711 & 0.825 & 0.004 & 0.786 & 1.002 \\
\hline$\theta_{F}$ & 0.697 & 0.021 & 0.649 & 0.729 & 0.002 & 0.004 & 1.171 \\
\hline$a_{1}$ & 0.237 & 0.085 & 0.100 & 0.422 & 0.002 & 0.104 & 1.004 \\
\hline$b_{2}$ & 0.698 & 0.050 & 0.587 & 0.791 & 0.004 & 0.310 & 1.013 \\
\hline$c_{3}$ & 0.890 & 0.060 & 0.770 & 1.007 & 0.001 & 0.187 & 1.001 \\
\hline$\rho_{a}$ & 0.544 & 0.187 & 0.165 & 0.830 & 0.031 & 0.625 & 1.011 \\
\hline$\rho_{q}$ & 0.695 & 0.039 & 0.596 & 0.760 & 0.004 & 0.576 & 1.006 \\
\hline$\rho_{s}$ & 0.682 & 0.068 & 0.547 & 0.827 & 0.006 & 0.952 & 1.000 \\
\hline$\mu_{q}$ & 0.006 & 0.005 & 0.001 & 0.018 & 0.000 & 0.965 & 1.000 \\
\hline$\mu_{y}$ & 0.273 & 0.138 & 0.100 & 0.623 & 0.020 & 0.574 & 1.010 \\
\hline$\mu_{r}$ & 0.850 & 0.252 & 0.312 & 1.221 & 0.034 & 0.007 & 1.287 \\
\hline$\sigma_{H}$ & 2.100 & 1.298 & 0.579 & 4.984 & 0.230 & 0.984 & 1.000 \\
\hline$\sigma_{F}$ & 0.775 & 0.362 & 0.307 & 1.647 & 0.031 & 0.032 & 1.064 \\
\hline$\sigma_{a}$ & 20.023 & 1.870 & 15.376 & 22.747 & 0.277 & 0.003 & 1.368 \\
\hline$\sigma_{q}$ & 0.800 & 0.135 & 0.590 & 1.122 & 0.015 & 0.723 & 1.003 \\
\hline$\sigma_{s}^{q}$ & 2.656 & 0.471 & 1.858 & 3.689 & 0.045 & 0.093 & 1.056 \\
\hline$\sigma_{\pi^{*}}$ & 0.412 & 0.043 & 0.335 & 0.503 & 0.000 & 0.924 & 1.000 \\
\hline$\sigma_{y^{*}}$ & 0.553 & 0.073 & 0.423 & 0.708 & 0.002 & 0.177 & 1.003 \\
\hline$\sigma_{r *}$ & 0.222 & 0.022 & 0.184 & 0.269 & 0.000 & 0.049 & 1.001 \\
\hline$\sigma_{r}$ & 0.374 & 0.059 & 0.268 & 0.500 & 0.003 & 0.486 & 1.004 \\
\hline
\end{tabular}

Notes: The numerical standard error (NSE) as given in Geweke (1999). The $p$-value is computed using $L=0.08$ in Geweke (1999). The B-G univariate "shrink factor" as in Brooks and Gelman (1998).

central banks care a lot about smoothing interest rate movements. Second, there is not a lot of weight placed on the output gap, a result consistent with a strong inflation targeting focus for these central banks. Finally, these central banks place virtually no weight on exchange rates.

Cross-country comparisons of the preference parameters reveal whether our three open economy inflation targeters possess similar objectives. Figure 4 graphs the posterior distributions of both the output stabilization parameter and the interest-ratesmoothing parameter for each country on the same axes. The degree to which each country shares similar stabilization objectives is illustrated by the degree of similarity between the posterior distributions.

To measure the closeness of two distributions, DeJong, Ingram, and Whiteman (1996) construct a metric using the Confidence Interval Criterion (CIC). The CIC is

$$
\mathrm{CIC}_{i j}=\frac{1}{1-\gamma} \int_{a}^{b} P_{j}\left(s_{i}\right) d s_{i},
$$


TABLE 7

Posterior Parameters and Convergence Diagnostics: New Zealand $\left(\mu_{q}=0\right)$

\begin{tabular}{|c|c|c|c|c|c|c|c|}
\hline & Post mean & Post std & $2.5 \%$ & $97.5 \%$ & NSE & $p$-value & B-G \\
\hline$\beta$ & 0.990 & 0.000 & 0.990 & 0.990 & 0.000 & 1.000 & 1.000 \\
\hline$\alpha$ & 0.450 & 0.000 & 0.450 & 0.450 & 0.000 & 1.000 & 1.000 \\
\hline$h$ & 0.812 & 0.036 & 0.752 & 0.891 & 0.005 & 0.999 & 1.000 \\
\hline$\sigma$ & 1.312 & 0.318 & 0.674 & 2.015 & 0.046 & 0.236 & 1.062 \\
\hline$\phi$ & 1.586 & 0.264 & 1.041 & 2.082 & 0.010 & 0.149 & 1.011 \\
\hline$\eta$ & 0.917 & 0.307 & 0.369 & 1.553 & 0.031 & 0.617 & 1.005 \\
\hline$\delta_{H}$ & 0.173 & 0.074 & 0.043 & 0.324 & 0.007 & 0.275 & 1.019 \\
\hline$\delta_{F}$ & 0.083 & 0.044 & 0.019 & 0.190 & 0.002 & 0.390 & 1.004 \\
\hline$\theta_{H}$ & 0.767 & 0.027 & 0.712 & 0.819 & 0.003 & 0.073 & 1.074 \\
\hline$\theta_{F}$ & 0.683 & 0.020 & 0.645 & 0.725 & 0.002 & 0.017 & 1.095 \\
\hline$a_{1}$ & 0.240 & 0.079 & 0.103 & 0.408 & 0.002 & 0.501 & 1.000 \\
\hline$b_{2}$ & 0.722 & 0.048 & 0.612 & 0.809 & 0.004 & 0.414 & 1.007 \\
\hline$c_{3}$ & 0.891 & 0.060 & 0.769 & 1.006 & 0.001 & 0.274 & 1.000 \\
\hline$\rho_{a}$ & 0.622 & 0.209 & 0.101 & 0.821 & 0.024 & 0.005 & 1.296 \\
\hline$\rho_{q}$ & 0.708 & 0.035 & 0.631 & 0.769 & 0.003 & 0.199 & 1.017 \\
\hline$\rho_{s}$ & 0.717 & 0.057 & 0.606 & 0.830 & 0.006 & 0.695 & 1.003 \\
\hline$\mu_{y}$ & 0.217 & 0.113 & 0.091 & 0.534 & 0.013 & 0.573 & 1.006 \\
\hline$\mu_{r}$ & 0.732 & 0.222 & 0.394 & 1.322 & 0.030 & 0.232 & 1.058 \\
\hline$\sigma_{H}$ & 1.325 & 1.558 & 0.629 & 6.497 & 0.089 & 0.004 & 1.348 \\
\hline$\sigma_{F}$ & 0.909 & 0.478 & 0.319 & 2.141 & 0.051 & 0.394 & 1.012 \\
\hline$\sigma_{a}$ & 17.959 & 1.596 & 15.579 & 21.365 & 0.246 & 0.044 & 1.164 \\
\hline$\sigma_{q}$ & 0.794 & 0.128 & 0.587 & 1.097 & 0.009 & 0.544 & 1.003 \\
\hline$\sigma_{s}^{q}$ & 2.633 & 0.454 & 1.738 & 3.530 & 0.041 & 0.003 & 1.114 \\
\hline$\sigma_{\pi^{*}}$ & 0.412 & 0.042 & 0.336 & 0.501 & 0.000 & 0.492 & 1.000 \\
\hline$\sigma_{y^{*}}$ & 0.546 & 0.072 & 0.417 & 0.702 & 0.002 & 0.368 & 1.001 \\
\hline$\sigma_{r^{*}}$ & 0.222 & 0.022 & 0.184 & 0.269 & 0.000 & 0.967 & 1.000 \\
\hline$\sigma_{r}$ & 0.338 & 0.047 & 0.255 & 0.441 & 0.003 & 0.080 & 1.018 \\
\hline
\end{tabular}

Notes: The numerical standard error (NSE) as given in Geweke (1999). The $p$-value is computed using $L=0.08$ in Geweke (1999). The B-G univariate "shrink factor" as in Brooks and Gelman (1998).

TABLE 8

Posterior Odds Model Comparison

\begin{tabular}{|c|c|c|c|}
\hline Country (Model, $M_{i}$ ) & $p\left(y \mid M_{i}\right)$ & $\ln \frac{p\left(y \mid M_{1}\right)}{p\left(y \mid M_{2}\right)}$ & Bayes factor \\
\hline Australia $(i=1)$ & $-1,955.0$ & & \\
\hline Australia $(i=2)$ & $-1,941.7$ & -13.3 & $5.97 \times 10^{5}$ \\
\hline Canada $(i=1)$ & $-1,815.6$ & & \\
\hline Canada $(i=2)$ & $-1,805.3$ & -10.3 & $2.97 \times 10^{4}$ \\
\hline New Zealand $(i=1)$ & $-1,994.6$ & & \\
\hline New Zealand $(i=2)$ & $-1,980.5$ & -14.1 & $1.33 \times 10^{6}$ \\
\hline
\end{tabular}

Notes: $M_{1}: \mu_{q}>0$ and $M_{2}: \mu_{q}=0$. Marginal likelihood for Geweke's $p=0.1$ are reported, where $p \in(0,1)$. The Bayes factor is calculated as $\frac{p\left(y \mid M_{2}\right)}{p\left(y \mid M_{1}\right)}$. These results are robust to alternative detrending methods. Results are available upon request.

where $P_{j}\left(s_{i}\right)$ is the distribution of the simulated model statistic and $s_{i}, i=1, \ldots, n$, are the distributions of interest where $a=\frac{\gamma}{2}$ and $b=1-a$ are particular quantiles of a reference distribution $D\left(s_{i}\right)$ the tails of which are truncated by the parameter $\gamma$. This implies that the CIC is in fact bounded by 0 and $(1-\gamma)^{-1}$ (such that the CIC 
TABLE 9

Posterior Odds Model Comparison under Linearly Detrended Data

\begin{tabular}{|c|c|c|c|}
\hline Country (Model, $M_{i}$ ) & $p\left(y \mid M_{i}\right)$ & $\ln \frac{p\left(y \mid M_{1}\right)}{p\left(y \mid M_{2}\right)}$ & Bayes factor \\
\hline Australia $(i=1)$ & -2083.8 & & \\
\hline Australia $(i=2)$ & -2001.2 & -82.6 & $7.46 \times 10^{35}$ \\
\hline Canada $(i=1)$ & -1932.9 & & \\
\hline Canada $(i=2)$ & -1909.4 & -23.5 & $1.61 \times 10^{10}$ \\
\hline New Zealand $(i=1)$ & -2132.4 & & \\
\hline New Zealand $(i=2)$ & -2056.8 & -75.6 & $6.80 \times 10^{32}$ \\
\hline
\end{tabular}

Notes: $M_{1}: \mu_{q}>0$ and $M_{2}: \mu_{q}=0$. Marginal likelihood for Geweke's $p=0.1$ are reported, where $p \in(0,1)$. The Bayes factor is calculated as $\frac{p\left(y \mid M_{2}\right)}{p\left(y \mid M_{1}\right)}$.
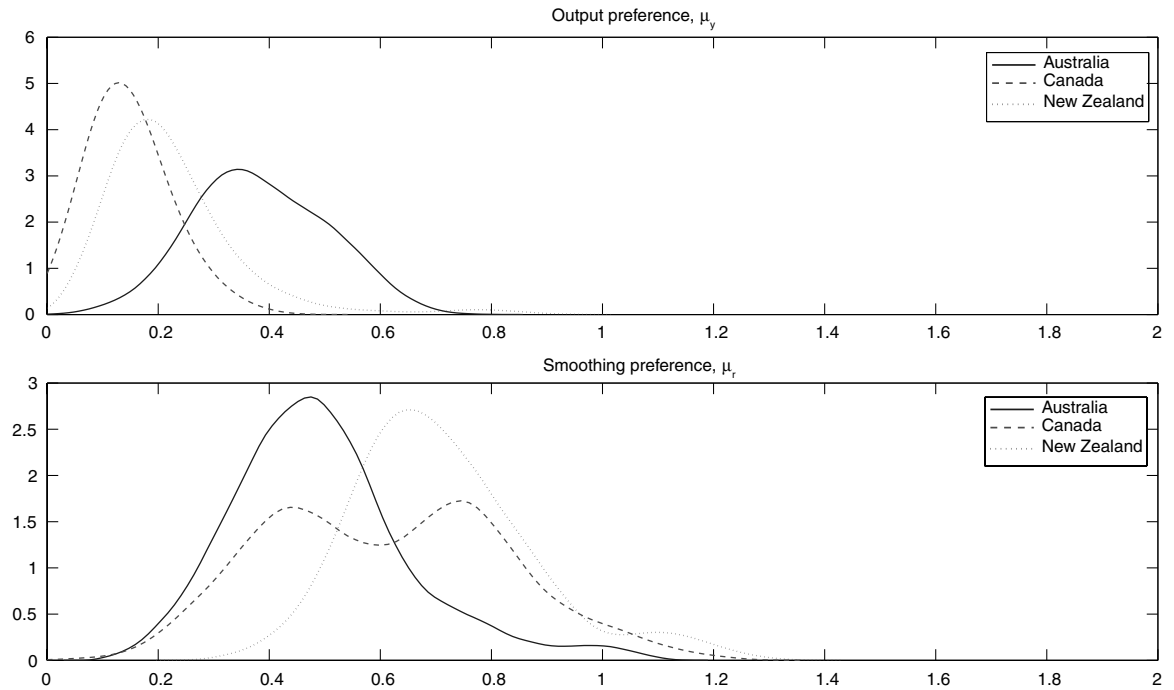

FIG. 4. Posterior Comparison of Loss Function Parameters.

is only bounded between 0 and 1 for the special case when $\gamma=0$ ). The CIC statistic can be thought of as measuring the overlap in two distributions.

A CIC statistic close to the upper bound $(1-\gamma)^{-1}$, implies the distributions are very similar. A CIC close to zero implies the distributions are not particularly similar because either the location of the distributions is different or the reference distribution is particularly diffuse.

DeJong, Ingram, and Whiteman (1996) advocate using the following measure as a test for difference in location of the distributions

$$
d_{j i}=\frac{E P_{j}\left(s_{i}\right)-E D\left(s_{i}\right)}{\sqrt{\operatorname{var}\left(D\left(s_{i}\right)\right)}}
$$


such that large difference in expected values (and hence expected location) generate large test statistics while diffusion in the reference distribution $D\left(S_{i}\right)$ reduces the test statistic.

Inspecting Figure 4, the output stabilization parameter in the top half of the figure shows that all three countries place some weight on output stabilization. Canada appears to put the least weight on output stabilization with the left-most posterior distribution with a posterior mode of 0.147 . The corresponding distribution for New Zealand is very similar in both shape and location, with a posterior mode of 0.217 . With $\gamma=0.1$ the CIC returns a value of 0.864 , indicating that Canada and New Zealand share a similar concern for output stabilization. The Australian posterior distribution places a higher weight on output stabilization with a posterior mode of 0.384 . The CIC between Australia and Canada is much smaller - 0.186 although the CIC returns a statistic of 0.475 for the overlap between output stabilization in Australia and New Zealand.

The panel in the bottom half of Figure 4 shows the overlap of the preference for interest rate smoothing across the three countries. All three countries show some interestrate-smoothing behavior. Australia appears to place the least weight on smoothing the interest rate, returning a posterior model of 0.493 while the corresponding parameter is 0.647 for Canada and 0.732 for New Zealand. However, the CIC statistics emphasize similarities rather than differences. The overlap in preferences for smoothing interest rates is 0.830 between Australia and Canada, 0.829 between Australia and New Zealand, and 1.0364 between Canada and New Zealand (which is greater than 1 since $\gamma=0.1$, implying $\left.(1-\gamma)^{-1} \approx 1.1\right)$.

A natural question is whether the overall macroeconomic objectives of each country are identical. This is a joint test of whether the distribution of the preferences for macroeconomic stabilization and interest rate smoothing are the same. Rather than averaging the CIC criterion across the preference parameters, we construct a multivariate version of the CIC by generating a three-dimensional histogram of joint draws from the posterior. For convenience we set $\gamma=0$ and compare the volumes generated by integrating over the preference parameters for each country. We use 500,000 draws from the posterior and use a total of 625 bins to characterize the joint distribution.

This joint test returns a high degree of similarity across the distributions. Between Australia and Canada, we find that $90.6 \%$ of the draws can be characterized by the same distribution; this figure remains high between Australia and New Zealand (93.4\%) and between Canada and New Zealand (94.3\%). Thus, our results indicate that the preferences of these three small open economy inflation targeters are, in fact, pretty similar.

\section{IMPLICATIONS FOR REDUCED-FORM SIMPLE POLICY RULE ANALYSES}

In this section, we provide the link between our empirical analysis of uncovering what central bank preferences are and the resulting implication for policy behavior. 
While it is straightforward to derive the mapping from preferences to equilibrium behavior for the central banks, the converse is not the case, if one begins the analysis from an ad hoc behavioral rule. Thus, analyses, such as Lubik and Schorfheide (2007), may not be very informative if one wishes to ask the sort of question we addressed in the previous sections.

The estimated Markov-perfect equilibrium in each of the models reported in Tables 2-7 implies a reduced-form optimal monetary policy decision rule. ${ }^{7}$ In this section, we show that our estimates across all sample data sets imply reduced-form policy rules that respond to exchange rate movements. This result remains, even in the case when the central bank has no explicit concern for stabilizing the exchange rate in its loss function. To conserve space, we only report the example from Australia.

A representation of the resulting (mean or median) Markov-perfect equilibrium rule for Australia, when $\mu_{q}>0$ can be expressed as:

$$
\begin{aligned}
r_{t}= & 0.16 r_{t-1}-0.11 c_{t}+0.04 \pi_{F, t}-0.05 \pi_{H, t}-0.23 q_{t}-0.01 s_{t}-0.11 y_{t}-0.01 \pi_{t} \\
& +0.01 \tilde{\pi}_{t}-0.03 \pi_{t-1}+\mathbf{P}_{2, s}((1-\alpha) 0.74)^{-1}\left[\Delta \psi_{F, t}-\Delta e_{t}-\pi_{t}^{*}+\pi_{t}\right] \\
& + \text { other exogenous terms, }
\end{aligned}
$$

where $\mathbf{P}_{2, s} \approx-0.04$ and $\alpha=0.4 .^{8}$

The averaged representation for the optimal reduced form policy rule for Australia, when $\mu_{q}=0$, has the following form

$$
\begin{aligned}
r_{t}= & 0.12 r_{t-1}-0.07 c_{t}-0.04 \pi_{H, t}+0.02 \pi_{F, t}-0.21 q_{t}-0.01 s_{t}-0.07 y_{t}-0.01 \pi_{t} \\
& +0.00 \tilde{\pi}_{t}-0.03 \pi_{t-1}+\mathbf{P}_{2, s}((1-\alpha) 0.75)^{-1}\left[\Delta \psi_{F, t}-\Delta e_{t}-\pi_{t}^{*}+\pi_{t}\right] \\
& + \text { other exogenous terms, }
\end{aligned}
$$

where $\mathbf{P}_{2, s} \approx-0.03$ and $\alpha=0.4$.

Across all three country data samples, the overall policy response elasticities when $\mu_{q}=0$ are quite similar in sign but more attenuated in magnitude to the case when $\mu_{q}>0$. This is especially the case for our response variable of interest: (i) the level of the real exchange rate and (ii) the response to nominal exchange rate growth.

This result shows that behavioral response to exchange rates is not inconsistent with a central bank that has no explicit concern for stabilizing movements in the real

7. The full set of results, computational methods, and further discussions are available from the authors upon request.

8. The variable associated with the parameter $\mathbf{P}_{2, s}((1-\alpha) 0.73)^{-1}$ comes from the terms-of-trade growth identity in equation (39) in the main paper, repeated here as:

$$
s_{t}-s_{t-1}=\pi_{F, t}-\pi_{H, t}+\epsilon_{s, t} .
$$

From this, and the relationship between terms of trade and the real exchange rate (equation (33) in the paper) and the nominal exchange rate (equation (32) in the paper), we have the expression, rewritten as:

$$
\epsilon_{s}=\frac{1}{1-\alpha}\left[\Delta \psi_{F, t}-\Delta e_{t}-\pi_{t}^{*}+\pi_{t}\right]-\pi_{F, t}+\pi_{H, t} .
$$


exchange rate. Furthermore, it provides an optimal policy basis for results found in existing work using ad hoc Taylor type rules (e.g., Lubik and Schorfheide 2007) that some central banks do respond to movements in nominal exchange rate growth. That the central banks still respond optimally to exchange rate movements even when $\mu_{q}$ $=0$ reflects the endogenous law-of-one-price gap feature of the Monacelli (2005)style model we use. Monacelli showed that in a model such as ours, it is no longer sufficient for policy to stabilize a measure of domestic goods price inflation and output gap. There still exists a monetary policy trade-off arising endogenously from the law-of-one-price gap in imperfect imports price pass through. This also justifies our assumption, and Monacelli's, of central banks having CPI inflation as an argument in the loss functions. In any case, one could always rewrite using equations (39) and (41), an expression for CPI inflation as

$$
\pi_{t}=\pi_{H}+\alpha\left(\Delta s_{t}-\epsilon_{s, t}\right),
$$

so that the central banks not only care about domestic goods inflation, but also variations to the growth rate in the terms of trade between home and foreign goods.

Therefore, the previous exercise of asking whether central banks explicitly care about exchange rate movements, can only be addressed by explicitly modeling and estimating their objective functions. We have shown in this exercise that, given policy preferences, the resulting reduced form policy rule encompasses the results of existing work using ad hoc Taylor-type rules, in terms of responses to exchange rate movements. However, the reverse analysis, using reduced-form rules, may not provide any conclusive evidence for deducing what central banks may care about. In fact, we reestimate the Lubik and Schorfheide (2007) simple rule in our model, in the following section.

\subsection{Simple Rules and Behavioral Response}

We now take the simple Taylor-type rule used in Lubik and Schorfheide (2007), and reestimate that in the context of our model and data set (which is defined over more time series variables). This exercise provides a simpler alternative description of central bank behavior. The simple rule specification is:

$$
r_{t}=\rho_{r} r_{t-1}+\left(1-\rho_{r}\right)\left(\psi_{\pi} \pi_{t}+\psi_{y} y_{t}+\psi_{\Delta e} \Delta e_{t}\right)+\varepsilon_{t}^{R},
$$

where $\rho_{r}, \psi_{\pi}, \psi_{y}, \psi_{\Delta e}$ are the policy responses to the lag of the nominal interest rate, inflation, the output gap, and the change in the nominal exchange rate, respectively, and $\varepsilon_{t}^{R}$ is an exogenous policy shock.

To address the question in Lubik and Schorfheide (2007), we examine two specifications: (i) with the central bank responding to the change in the nominal exchange rate (that is, allowing $\Psi=0$ ) and (ii) imposing no response to the change in the nominal exchange rate (that is, $\Psi=0$ ). The results from estimation of these simple policy rules are presented in Table 10. 
TABLE 10

Posterior Odds Model Comparison under the Lubik and Schorfheide (2007) Simple Rule

\begin{tabular}{|c|c|c|c|c|c|c|}
\hline Parameter & Mean & Probability int. & & Dist & Mean & Std der \\
\hline \multicolumn{7}{|c|}{ Australia } \\
\hline \multicolumn{7}{|c|}{ Restricted case: $\psi_{\Delta e}=0, \log$ data density -1371.422} \\
\hline$\rho_{R}$ & 0.698 & 0.630 & 0.769 & Beta & 0.5 & 0.2 \\
\hline$\phi_{1}$ & 2.077 & 1.771 & 2.372 & Gamma & 1.5 & 0.3 \\
\hline$\phi_{2}$ & 0.342 & 0.246 & 0.437 & Gamma & 0.5 & 0.1 \\
\hline \multicolumn{7}{|c|}{ Unrestricted case, log data density -1370.844} \\
\hline$\rho_{R}$ & 0.710 & 0.656 & 0.769 & Beta & 0.5 & 0.2 \\
\hline$\phi_{1}$ & 2.080 & 1.847 & 2.320 & Gamma & 1.5 & 0.3 \\
\hline$\phi_{2}$ & 0.339 & 0.253 & 0.414 & Gamma & 0.5 & 0.1 \\
\hline$\phi_{3}$ & 0.009 & 0.000 & 0.023 & Uniform & -0.5 & 0.5 \\
\hline \multicolumn{7}{|c|}{$\begin{aligned} & \text { Canada } \\
\text { Restricted case: } \psi & =0, \log \text { data density }-1219.062\end{aligned}$} \\
\hline & & Restricted case: $\psi_{\Delta e}$ & $=0, \log \mathrm{c}$ & sity -121 & & \\
\hline$\rho_{R}$ & 0.768 & 0.736 & 0.798 & Beta & 0.5 & 0.2 \\
\hline$\phi_{1}$ & 1.322 & 1.226 & 1.430 & Gamma & 1.5 & 0.3 \\
\hline$\phi_{2}$ & 0.296 & 0.208 & 0.379 & Gamma & 0.5 & 0.1 \\
\hline \multicolumn{7}{|c|}{ Unrestricted case, log data density -1222.524} \\
\hline$\rho_{R}$ & 0.741 & 0.689 & 0.794 & Beta & 0.5 & 0.2 \\
\hline$\phi_{1}$ & 1.253 & 1.194 & 1.318 & Gamma & 1.5 & 0.3 \\
\hline$\phi_{2}$ & 0.233 & 0.181 & 0.287 & Gamma & 0.5 & 0.1 \\
\hline$\phi_{3}$ & 0.002 & 0.002 & 0.002 & Uniform & 0 & 0.5 \\
\hline \multicolumn{7}{|c|}{$\begin{array}{l}\text { New Zealand } \\
e=0, \log \text { data }\end{array}$} \\
\hline$\rho_{R}$ & 0.674 & 0.601 & 0.749 & Beta & 0.5 & 0.2 \\
\hline$\phi_{1}$ & 2.017 & 1.619 & 2.448 & Gamma & 1.5 & 0.3 \\
\hline$\phi_{2}$ & 0.393 & 0.273 & 0.515 & Gamma & 0.5 & 0.1 \\
\hline \multicolumn{7}{|c|}{ Unrestricted case, log data density -1445.536} \\
\hline$\rho_{R}$ & 0.666 & 0.592 & 0.742 & Beta & 0.5 & 0.2 \\
\hline$\phi_{1}$ & 1.940 & 1.620 & 2.257 & Gamma & 1.5 & 0.3 \\
\hline$\phi_{2}$ & 0.405 & 0.287 & 0.525 & Gamma & 0.5 & 0.1 \\
\hline$\phi_{3}$ & 0.036 & 0.000 & 0.079 & Uniform & 0 & 0.5 \\
\hline
\end{tabular}

Comparison of the log data densities shows evidence that the RBA responds to changes in the exchange rate. The Bayes factor is 1.78. That is, one would have to place a weight of 1.78 on the RBA not responding to nominal exchange rate growth to find both propositions equally likely). Canada does not respond to the change in the exchange rate (the Bayes factor is 0.03) and New Zealand does respond to the change in the exchange rate (the Bayes factor is 6.25). The Bayes factor for the model comparison exercise in the case of Canada is negligibly small. One might argue for a model of a Bank of Canada operating a simple rule with exchange rate response is just as equally probable as one without.

These results are contrary to Lubik and Schorfheide (2007) who find that Australia and New Zealand do not respond to change in the exchange rate but find some evidence that Canada does respond to changes in the exchange rate. The difference in our result to Lubik and Schorfheide is not surprising. A key omission from the Lubik and Schorfheide paper is the lack of an endogenous terms of trade specification and the lack of imperfect pass-through of nominal exchange rate changes into domestic import prices. Lubik and Schorfheide note 
One issue is our assumption of exogenous terms of trade movements, another is the lack of imperfect pass-through of nominal exchange rate changes into domestic import prices. Overall model misspecification is of concern as it can lead to biased parameter estimates, prevent identification of the true structural parameters and may imply incorrect model selection.

In addition, there is no endogenous persistence in the Lubik and Schorfheide (2007) Phillips equation. The persistence in inflation is solely driven from the shocks and a Phillips equation is more likely to fit the data (see, e.g., Fukac and Pagan Forthcoming), if one introduces endogenous persistence in the inflation process.

Furthermore, Lubik and Schorfheide (2007) estimate on a longer data set (from 1983Q1 to 2002Q4 for Australia and Canada and from 1988Q1 to 2002Q4 for New Zealand) that contains information from the preinflation targeting period for these countries. It is likely that estimation on a single monetary regime produces tighter estimates than the Lubik and Schorfheide paper that spans both the pre-inflation targeting era and the inflation-targeting period.

In summary, our result from estimating the simple policy rule of Lubik and Schorfheide (2007) within our model and data set corroborates the result derived from optimal policy in the previous sections. Specifically, both approaches yielded positive behavioral response of policy to nominal exchange rate growth. However, the simple rule approach is only just that-it cannot tell us more about what might explicitly concern central banks.

\section{CONCLUSION}

We estimate the macroeconomic policy objectives of the central banks of Australia, Canada, and New Zealand within the context of an optimizing DSGE model. Our parameter estimates reveal the objectives of these small open economy inflation targeters. We find key differences in the structural parameters of each economy that imply different behavior in the setting of monetary policy across countries-even if these countries share identical monetary policy objectives.

We emphasize the similarities rather than the differences in the macroeconomic objectives of the central banks of Australia, Canada, and New Zealand. Over the period considered, all three central banks show no concern for mitigating exchange rate volatility as an objective in its own right. However, all three central banks show a substantial concern for interest rate smoothing. The RBA shows the most desire to mitigate volatility in the output gap but in all three cases the estimated weight on the output gap is substantially lower than the weight on the deviation of annual inflation from target. Nevertheless, all central banks would be sensibly classified as flexible in their approach to inflation targeting.

We further showed that the resulting optimal policy rule still responds to exchange rate movements, even in the case where the central banks do not explicitly care about exchange rate stabilization. We also estimated a class of simple rules, as in Lubik and 
Schorfheide (2007), as an alternative representative of central bank behavior. While our results here are opposite to that of Lubik and Schorfheide, they corroborate the exchange rate response result in the optimal policy rules. Furthermore, the difference in our findings relative to Lubik and Schorfheide confirm their doubts on their own results and their conjecture that a richer model with endogenous terms of trade and imperfect imports price pass through may alter their model comparison results.

Our analysis has important implications for assessing the accountability and transparency of monetary policy. By jointly estimating the parameter estimates conditional on the same DSGE model we can make inferences about objectives conditional on the environment each central bank operates under. Such joint estimates result in very different conclusions relative to uninformed inference based on the unconditional distributions of goal variables such as annual inflation, the output gap, interest rates and the exchange rate. Future work could usefully extend the model to incorporate the potential effects of labor market behavior, credit constraints, and policy making under model uncertainty on the estimates of central banks' objectives.

\section{APPENDIX A: LOG-LINEAR APPROXIMATIONS TO FIRMS' OPTIMAL PRICING RULE}

\section{A.l Domestic Goods Pricing}

Given our specific assumption on period utility of households, rewrite the firstorder condition in (23), using the s-period iterate on the Euler operator (10) to replace $Q_{t, t+s}$, as

$$
\begin{aligned}
& \mathbb{E}_{t} \sum_{s=0}^{\infty}\left(\beta \theta_{H}\right)^{s} \frac{\left(C_{t+s}-H_{t+s}\right)^{-\sigma}}{P_{t+s}} Y_{t+s}(i) \\
& \quad \times\left[\tilde{P}_{H, t}\left(\frac{P_{H, t+s-1}}{P_{H, t-1}}\right)^{\delta_{H}}-\left(\frac{\varepsilon}{\varepsilon-1}\right) P_{H, t+s} M C_{H, t+s} \exp \left(\epsilon_{H, t+s}\right)\right]=0 .
\end{aligned}
$$

Log-linearize this around the deterministic steady state to obtain

$$
\begin{aligned}
\tilde{p}_{H, t} & -\delta_{H} p_{H, t-1} \\
\approx & \left(1-\beta \theta_{H}\right) \mathbb{E}_{t} \sum_{s=0}^{\infty}\left(\beta \theta_{H}\right)^{s}\left[p_{H, t+s}-\delta_{H} p_{H, t+s-1}+m c_{H, t+s}+\epsilon_{H, t+s}\right] \\
= & \left(1-\beta \theta_{H}\right)\left[p_{H, t}-\delta_{H} p_{H, t-1}+m c_{H, t}+\epsilon_{H, t}\right]+\beta \theta_{H}\left(1-\beta \theta_{H}\right) \mathbb{E}_{t} \sum_{s=0}^{\infty}\left(\beta \theta_{H}\right)^{s} \\
& \times\left[p_{H, t+s+1}-\delta_{H} p_{H, t+s}+m c_{H, t+s+1}+\epsilon_{H, t+s+1}\right] .
\end{aligned}
$$

This expression can be written recursively as

$$
\begin{aligned}
& \tilde{p}_{H, t}-\delta_{H} p_{H, t-1} \approx\left(1-\beta \theta_{H}\right)\left[p_{H, t}-\delta_{H} p_{H, t-1}+m c_{H, t}+\epsilon_{H, t}\right] \\
& \quad+\beta \theta_{H}\left[\mathbb{E}_{t} \tilde{p}_{H, t+1}-\delta_{H} p_{H, t-1}\right] .
\end{aligned}
$$


Log-linearizing (19) yields

$$
p_{H, t}=\left(1-\theta_{H}\right) \tilde{p}_{H, t}+\theta_{H} p_{H, t-1}+\theta_{H} \delta_{H} \pi_{H, t-1} .
$$

Substituting (A2) into (A1) yields the expression (24).

Now, equating firms' labor demand (22) to households labor supply (9)

$$
\frac{M C_{H, t} \epsilon_{a, t} P_{H, t}}{P_{t}}=\left(C_{t}-H_{t}\right)^{\sigma} N_{t}^{\varphi} .
$$

Log-linearizing this, and using the log-linearized production function $y_{t}=n_{t}+\epsilon_{a, t}$, we have

$$
m c_{H, t}=p_{t}-p_{H, t}+\frac{\sigma}{1-h}\left(c_{t}-h c_{t-1}\right)+\varphi y_{t}-(1+\varphi) \epsilon_{a, t} .
$$

Utilizing the log-linearized CPI index that implies $p_{t}-p_{H, t}=-\alpha\left(p_{H, t}-p_{F, t}\right)=$ $\alpha s_{t}$, and also (14), in (A4) we obtain (25).

\section{A.2 Imports Pricing}

Rewrite (30) as

$$
\begin{aligned}
& \mathbb{E}_{t} \sum_{s=0}^{\infty}\left(\beta \theta_{F}\right)^{s} \frac{\left(C_{t+s}-H_{t+s}\right)^{-\sigma}}{P_{t+s}} Y_{F, t+s}(j) \\
& \quad \times\left[\tilde{P}_{F, t}\left(\frac{P_{F, t+s-1}}{P_{F, t-1}}\right)^{\delta_{F}}-\left(\frac{\varepsilon}{\varepsilon-1}\right) \tilde{e}_{t+s} P_{F, t+s}^{*}(j) \exp \left(\epsilon_{F, t+s}\right)\right]=0 .
\end{aligned}
$$

Log-linearizing, and substituting with $\psi_{F, t+s}+\epsilon_{F, t+s}=e_{t+s}+p_{t+s}^{*}$, we obtain

$$
\begin{aligned}
& \tilde{p}_{F, t}-\delta_{F} p_{F, t-1} \approx\left(1-\beta \theta_{F}\right) \mathbb{E}_{t} \sum_{s=0}^{\infty}\left(\beta \theta_{F}\right)^{s} \\
& \quad \times\left[p_{F, t+s}+\psi_{F, t+s}+\epsilon_{F, t+s}-\delta_{F} p_{F, t+s-1}\right] .
\end{aligned}
$$

Log-linearize (27) to get

$$
p_{F, t}=\left(1-\theta_{F}\right) \tilde{p}_{F, t}+\theta_{F} p_{F, t-1}+\theta_{F} \delta_{F} \pi_{F, t-1} .
$$

Making use of the last two expressions yields (31).

\section{APPENDIX B: PSEUDO-CODE FOR MCMC PROCEDURE}

Algorithm 1. The RW-metropolis algorithm for a linear RE model:

1. Begin with an initial prior $\theta_{0} \in \Theta$ and its corresponding prior density $p\left(\theta_{0} \mid M\right)$ for model $M$. 
2. Solve the linear RE model to obtain (46) and construct observation equation (47).

3. For each $n=0,1, \ldots N$, Use (46)-(47), the given data set $y=\left\{y_{t}^{o}\right\}_{t=0}^{T}$, and $\theta_{n}$ to compute the model likelihood, $L\left(\theta_{n} \mid y, M\right)$ using a Kalman filter. Then calculate the associated posterior density, $p\left(\theta_{n} \mid y, M\right)=\frac{p\left(\theta_{n} \mid M\right) L\left(\theta_{n} \mid y, M\right)}{\int_{\Theta} p\left(\theta_{n} \mid M\right) L\left(\theta_{n} \mid y, M\right) d \mu\left(\theta_{n}\right)}$.

4. Generate a new candidate draw using a random walk model: $\theta_{n+1}=\theta_{n}+z_{n+1}$, where we assume $z_{n+1} \sim N(0, s \Sigma)$, and $s>0$ is a scalar factor for scaling the size of the jump in the draws. Compute the associated posterior density, $p$ $\left(\theta_{n+1} \mid y, M\right)$ by repeating Step 3, for $\theta_{n+1}$.

5. Compute the acceptance probability, $\alpha\left(\theta_{n}, \theta_{n+1} \mid y\right):=\min \left\{\frac{p\left(\theta_{n+1} \mid y, M\right)}{p\left(\theta_{n} \mid y, M\right)}, 1\right\}$.

6. Repeat Steps 3-4 for $N$ sufficiently large to ensure that the sequence $\left\{\theta_{n}\right\}_{n=0}^{N}$ is drawn from an ergodic distribution, $\pi$.

7. Under some sufficient conditions, we can apply the ergodic theorem of an irreducible Markov chain and approximate the posterior expected value of a (bounded) function of interest, $f(\theta)$ using the sample mean of the functions, $N^{-1} \sum_{n}^{N} f\left(\theta_{n}\right)$.

\section{LITERATURE CITED}

Beechey, Meredith, Nargis Bharucha, Adam Cagliarini, David Gruen, and Christopher Thompson. (2000) "A Small Model of the Australasian Macroeconomy." Research Discussion Paper 2000/05, Reserve Bank of Australia.

Benigno, Pierpaolo, and Michael Woodford. (2008) "Linear-Quadratic Approximation of Optimal Policy Problems.” Discussion Paper 0809-01, Columbia University, Department of Economics.

Bergin, Paul, Hyung-Cheol Shin, and Ivan Tchakarov. (2007) "Does Exchange Rate Volatility Matter for Welfare? A Quantitative Investigation of Stabilization Policies." European Economic Review, 51, 1041-58.

Bernanke, Ben, Thomas Laubach, Frederic Mishkin, and Adam Posen. (1999) Inflation Targeting: Lessons from the International Experience. Princeton, NJ: Princeton University Press.

Black, Richard, Vincenzo Cassino, Aaron Drew, Eric Hansen, Benjamin Hunt, David Rose, and Alasdair Scott. (1997) "The Forecasting and Policy System: The Core Model." Research Paper 43, Reserve Bank of New Zealand.

Brooks, Stephen P., and Andrew Gelman. (1998) "Alternative Methods for Monitoring Convergence of Iterative Simulations." Journal of Computational and Graphical Studies, 7, 434-55.

Castelnuovo, Efrem, and Paolo Surico. (2004) "Model Uncertainty, Optimal Monetary Policy and the Preferences of the Fed." Scottish Journal of Political Economy, 51, 105-26.

Cecchetti, Stephen, Margaret M. McConnell, and Gabriel Perez-Quiros. (2001) "Policymakers Revealed Preferences and the Output-Inflation Variability Trade-Off." The Manchester School, 70, 596-618.

Coletti, Donald, Benjamin Hunt, David Rose, and Robert Tetlow. (1996) "The Bank of Canada's New Quarterly Projection Model Part 3.” Bank of Canada Technical Report 75, Bank of Canada. 
DeJong, David N., Beth F. Ingram, and Charles Whiteman. (1996) "A Bayesian Approach to Calibration." Journal of Business and Economic Statistics, 14, 1-10.

Del Negro, Marco, and Frank Schorfheide. (2005) "Monetary Policy Analysis with Potentially Misspecified Models.” Working Paper 2005-26, Federal Reserve Bank of Atlanta.

Dennis, Richard. (2004) "Inferring Policy Objectives from Economic Outcomes." Oxford Bulletin of Economic Statistics, 66, 735-64.

Dennis, Richard. (2006) “The Policy Preference of the US Federal Reserve.” Journal of Applied Econometrics, 21, 55-77.

Favero, Carlo, and Riccardo Rovelli. (2003) "Macroeconomic Stability and the Preferences of the Fed: A Formal Analysis, 1961-98." Journal of Money Credit and Banking, 35, 546-56.

Fukac, Martin, and Adrian Pagan. (Forthcoming) "Limited Information Estimation and Evaluation of DSGE Models." Journal of Applied Econometrics.

Geweke, John. (1999) "Using Simulation Methods for Bayesian Econometric Models: Inference, Development and Communication." Econometric Reviews, 18, 1-26.

Hargreaves, David, Hannah Kite, and Bernard Hodgetts. (2006) "Modelling New Zealand inflation in a Phillips curve." Reserve Bank of New Zealand Bulletin, 69, 23-37.

Justiniano, Alejandro, and Bruce Preston. (Forthcoming) "Monetary Policy and Uncertainty in an Empirical Small Open Economy Model." Journal of Applied Econometrics.

Levin, Andrew, and John Williams. (2003) "Robust Monetary Policy with Competing Reference Models." Journal of Monetary Economics, 50, 945-75.

Lowe, Philip, and Luci Ellis. (1997) "The Smoothing of Official Interest Rates." In Monetary Policy and Inflation Targeting, edited by P. Lowe, pp. 286-312. Canberra, Australia: Reserve Bank of Australia.

Lubik, Thomas, and Frank Schorfheide. (2005) "A Bayesian Look at New Open Economy Macroeconomics.” NBER Macroeconomics Annual, 313-66.

Lubik, Thomas, and Frank Schorfheide. (2007) "Do Central Banks Respond to Exchange Rate Movements? A Structural Investigation.” Journal of Monetary Economics, 54, 1069-87.

Monacelli, Tommaso. (2005) “Monetary Policy in a Low Pass-Through Environment." Journal of Money, Credit and Banking, 37, 1047-66.

Nimark, Kristoffer. (2006) "Optimal Monetary Policy with Real-Time Signal Extraction from the Bond Market." Research Discussion Paper 2006/05, Reserve Bank of Australia.

Obstfeld, Maurice, and Kenneth Rogoff. (1998) "Risk and Exchange Rates.” NBER Working Paper 6694, National Bureau of Economic Research.

Ozlale, Umit. (2005) "Price Stability vs. Output Stability: Tales of the Federal Reserve Administrations." Journal of Economic Dynamics and Control, 27, 1595-1610.

Rabanal, Pau, and Juan F. Rubio-Ramírez. (2005) "Comparing New Keynesian Models of the Business Cycle: A Bayesian Approach.” Journal of Monetary Economics, 52, 115166.

Rudebusch, Glenn, and Lars E. O. Svensson. (1999) "Policy Rules for Inflation Targeting." In Monetary Policy Rules, edited by J. B. Taylor, pp. 203-53. Chicago: University of Chicago Press.

Salemi, Michael. (1995) "Revealed Preferences of the Federal Reserve: Using Inverse Control Theory to Interpret the Policy Equation of a Vector Autoregression." Journal of Business and Economic Statistics, 13, 419-33. 
Smets, Frank, and Raf Wouters. (2003) "An Estimated Dynamic Stochastic General Equilibrium Model of the Euro Area." Journal of the European Economic Association, 1, 1123-75.

Svensson, Lars E. O. (2000) “Open-Economy Inflation Targeting." Journal of International Economics, 50, 155-83.

Svensson, Lars E. O. (2005) "Optimal Inflation Targeting: Further Developments of Inflation Targeting." Unpublished manuscript, Available at http://www.princeton.edu/svensson/.

Woodford, Michael. (2003). Interest and Prices: Foundations of a Theory of Monetary Policy. Princeton, NJ: Princeton University Press. 